\title{
Comparative transcriptome analysis reveals new molecular pathways for cucumber genes related to sex determination
}

\author{
Magdalena Pawełkowicz ${ }^{1}$ - Leszek Pryszcz ${ }^{2} \cdot$ Agnieszka Skarzyńska $^{1} \cdot$ Rafał K. Wóycicki $^{1,3} \cdot$ Kacper Posyniak $^{1}$. \\ Jacek Rymuszka ${ }^{1}$. Zbigniew Przybecki ${ }^{1}$. Wojciech Pląder ${ }^{1}$
}

Received: 26 July 2018 / Accepted: 18 January 2019 / Published online: 5 February 2019

(c) The Author(s) 2019

\begin{abstract}
Key message Transcriptome data and qPCR analysis revealed new insight into genes regulatory mechanism related to cucumber sex determination.

Abstract Cucumber (Cucumis sativus L.) is an economically important crop cultivated worldwide. Enhancing the genomic resources for cucumber may enable the regulation of traits relevant to crop productivity and quality. Sequencing technologies and bioinformatics tools provide opportunities for the development of such resources. The aims of this study were to identify and characterize the genes involved in sex determination and flower morphogenesis in cucumber isogenic lines that differed regarding flower sex type. We obtained transcripts for 933 genes related to shoot apex development, among which 310 were differentially expressed genes (DEGs) among the male, female, and hermaphroditic lines. We performed gene ontology and molecular network analyses and explored the DEGs related to already known processes like: hormone synthesis and signaling, lipid and sugar metabolism; and also newly discovered processes related to cell wall, membrane, and cytoskeleton modifications; ion homeostasis which appears to be important for ethylene perception and signaling, and genes expression mediated by transcription factors related to floral organ identities. We proposed a new model of regulatory mechanism network of sex development in cucumber. Our results may be useful for clarifying the molecular genetics and the functional mechanisms underlying the sex determination processes.
\end{abstract}

Keywords Cucumber (Cucumis sativus) $\cdot$ Sex determination $\cdot$ Flower development $\cdot$ Transcriptome profiling $\cdot$ Illumina sequencing

Communicated by Richard G.H. Immink.

Electronic supplementary material The online version of this article (https://doi.org/10.1007/s00497-019-00362-z) contains supplementary material, which is available to authorized users.

Magdalena Pawełkowicz

magdalena_pawelkowicz@sggw.pl

1 Department of Plant Genetics, Breeding and Biotechnology, Warsaw University of Life Sciences, Nowoursynowska 159, 02-776 Warsaw, Poland

2 Laboratory of Zebrafish Developmental Genomics, International Institute of Molecular and Cell Biology, Ks. Trojdena 4, 02-109 Warsaw, Poland

3 Present Address: Philip Morris International R\&D, Philip Morris Products S.A., 2000 Neuchâtel, Switzerland

\section{Introduction}

Cucumber (Cucumis sativus), which belongs to the family Cucurbitaceae, is an economically and nutritionally important vegetable crop cultivated worldwide. Cucumber yield depends not only on favorable growth conditions, but also on efficient pollination as well as the type and quantity of flowers that develop on plants (Pawełkowicz et al. 2016a). The diverse cucumber flowers can be divided into the following three main types: staminate (male), pistillate (female), and hermaphroditic (both male and female organs). Plants in the family Cucurbitaceae fail to produce fruit when pollination does not occur with the exception of hybrid variants only with female flowers. Cucumbers usually have female and male flowers on the same plant, meaning that they are self-pollinating and do not have to receive pollen from other plants. In hybrid varieties, the number of female flowers on the plant is enhanced in order to increase the yield of fruits, but here pollination is complicated. Bumblebees and 
honeybees, which are the most effective cucumber pollinators, transfer pollen from male to female flowers, ultimately resulting in the production of fruits. In rare cases, flowers are manually pollinated. Few commercial cucumber (hybrid varieties) mostly those grown in a greenhouse, could produce fruit in the absence of pollination, so-called parthenocarpic (seedless); this necessitates the growth of gynoecious plants with only female flowers. Although such plants do not produce pollen of their own, they can be still fertilized by other varieties of cucumbers by bees. Fruits resulting from pollination will be often deformed.

On the basis of the position and occurrence of different flower types on the stem, plants can be divided into the following types: monoecious (male and female flowers), gynoecious (only female flowers), andromonoecious (hermaphroditic and male flowers), hermaphroditic (only hermaphroditic flowers), trimonoecious (female, male, and hermaphroditic flowers), and androecious (only male flowers). Beside the lack of ovary, male flowers differ from female flowers regarding appearance also by having shorter stem. Moreover, the female flower produces an ovary in a small fruit shape, at the base of the stem. Hermaphroditic flowers consist of a round and short ovary, and fruits derived from these flowers are formless and have no commercial value. Elucidating the mechanism underlying flower development may generate new information regarding regulatory activities relevant to manipulating flower sex determination in cucumber as well as in other species. Although sex determination is one of the key developmental processes during plant sexual reproduction, it remains poorly understood.

Several studies have attempted to characterize the molecular aspects of cucumber sex determination. During the early cucumber flower development stages, floral primordia are bisexual and contain the initial forms of anthers and pistils. In this species, sex determination requires the selective arrested development of the staminate or pistillate primordia (Bai et al. 2004). Cucumber sex expression is mainly determined by the $F, m, a, g y$, and $h$ genes. The female $(F)$ gene encodes a 1-aminocyclopropane-1-carboxylic acid synthase (CsACS1G) that regulates the number of female flowers (Mibus and Tatlioglu 2004; Trebitsh et al. 1997). The andromonoecious gene $(M)$ also encodes a putative 1-aminocyclopropane-1-carboxylic acid synthase (CsACS2), while the $m$ allele is mutated at a conserved site (resulting in the Gly33Cys amino acid change). The mutated enzyme exhibits decreased activity (Boualem et al. 2008; Li et al. 2009). The $F$ gene promotes femaleness, while the $m$ gene regulates the appearance of hermaphroditic flowers on the plant. Both genes are involved in ethylene synthesis and considerably affect sex determination by enhancing femaleness ( $\mathrm{Li}$ et al. 2012). Sex expression can be also influenced by many environmental factors, including the photoperiod, temperature, and exposure to plant hormones (e.g., auxin and gibberellins) (Malepszy and Niemirowicz-Szczytt 1991; Perl-Treves 1999; Yamasaki et al. 2005). The CsACS2 expression level is correlated with ethylene production, and may induce the expression of $C s A C S$ genes, suggesting there is positive feedback ( $\mathrm{Li}$ et al. 2012). There are relatively few reports describing $A / a, G y / g y$, and $H / h$ genes. According to a recent report, the $a$ gene may be related to $C s A C S 11$, which encodes another ACS protein in the ethylene biosynthesis pathway (Boualem et al. 2015). The earlier studies showed that the $a$ gene may be associated with CsRAN1, which encodes a copper transporter (Terefe 2005). On the basis of sex determination in Cucumis melo, gy can be assumed to be related to CsWIP (Boualem et al. 2015), which encodes a transcription factor with zinc finger domains and could be related to a serine/threonine kinase gene, CSPSTK1 (Pawełkowicz et al. 2012). Even though the sex expression is extensively studied (Przybecki et al. 2003, 2004; Wu et al. 2010), there is still very little information about the genes responsible for sex determination in cucumber.

Characterizing the processes leading to flower sex determination has great practical applications, as the sex of a flower or plant often limits how the plant is bred and cultivated. Herein, we present our transcriptome data concerning the shoot apex and leaves of cucumber lines that differ regarding sex. Furthermore, genes differentially expressed among the male, female, and hermaphroditic flowers were investigated to reveal differences in the regulation of key pathways. We proposed for the first time regulatory networks of proteins which are related to sex determination, and based on the functional annotation, we propose the new hypothetical scheme presenting the new processes with identified herein factors related to flower sex formation.

Our data represent an important genetic resource for clarifying the molecular mechanisms regulating cucumber sex determination and flower morphogenesis. The results of this study may be useful for future gene expression and functional genomic studies as well as cucumber breeding.

\section{Materials and methods}

\section{Plant materials and RNA isolation}

The following six cucumber lines that varied regarding flower sex type were taken for RNA sequencing (RNA-seq) analysis: two male samples (B10 and 859), two female samples (2gg and Gy3), and two hermaphroditic samples (2667 and Hgy3). Plants were cultivated in plastic pots in a greenhouse with a 16 -h light $\left(25-27^{\circ} \mathrm{C}\right) / 8$-h dark $\left(18-20^{\circ} \mathrm{C}\right)$ photoperiod. The light intensity (i.e., photosynthetically active radiation) in the greenhouse was $1500 \mu \mathrm{mol} \mathrm{m}^{-2} \mathrm{~s}^{-1}$. For a subsequent RNA isolation, leaves and the shoot apex (with newly formed, $<1 \mathrm{~mm}$ long floral buds) were collected, 
frozen in liquid nitrogen, and stored at $-80{ }^{\circ} \mathrm{C}$. Total RNA extracted from the leaves of six lines was pooled to form a representative sample of vegetative organs for a transcriptome analysis. The RNA extracted from the shoot apex of each line was analyzed separately. Total RNA was extracted using the TRIzol reagent (Invitrogen, Waltham, MA, USA). The concentration (optical density $260 \mathrm{~nm} / 280 \mathrm{~nm}$ ratio) and quality (optical density $260 \mathrm{~nm} / 230 \mathrm{~nm}$ ratio) of the extracted RNA were determined with the NanoDrop 2000 spectrophotometer (Thermo Fisher Scientific, Waltham, MA, USA). The RNA concentration was adjusted to $100 \mathrm{ng} \mu \mathrm{L}^{-1}$. For the quantitative real-time polymerase chain reaction (qPCR) analysis, RNA was treated with DNaseI from the TURBO DNA-free kit (Ambion, Austin, TX, USA) and then checked by PCR to ensure that there was no contaminating DNA. First-strand cDNA was synthesized using the HighCapacity cDNA Reverse Transcription Kit (Thermo Fisher Scientific, Waltham, MA, USA).

\section{RNA sequencing library construction and Illumina sequencing}

Approximately 5-10 $\mu \mathrm{g}$ total RNA was used as the template for constructing RNA-seq libraries. The subsequent purification of polyadenylated RNA as well as the RNA fragmentation, cDNA synthesis, and PCR amplification were completed according to the Illumina RNA-seq protocol (Illumina, Inc., San Diego, CA, USA).Two replicas of each sex-specific library from shoot apex and leaves were sequenced using an Illumina Genome Analyzer at the Aqencourt-Beckman Coulter Genomics, USA. As a technical control of the experiment, the internal standard was used according to the company's procedures. Single-end sequence reads (35-40 bp) were generated, and the RNA-seq read quality was evaluated based on the Illumina purity filter, percentage of low-quality reads, and the distribution of phredlike scores during each cycle. The data presented herein passed the quality control filtering based on these metrics. Sequences are available in the Sequence Read Archive of the National Center for Biotechnology Information (BioProject PRJNA359788).

\section{Gene annotation}

Cucumis sativus $\mathrm{L}$. genes were annotated using the BLAST + 2.2.26 program with the following parameters: blastp -F "mS" -b 1500 -v 1500 -e 0.001 -M BLOSUM45, and further filtered with an e-value cutoff of $1 \mathrm{e}-03$ and the InterProScan (version 5) program (Jones et al. 2014). The unigenes were validated and annotated by aligning them to sequences from the following databases: Phytozome (Goodstein et al. 2012), PANTHER (protein analysis through evolutionary relationships) (Mi et al. 2013), Eukaryotic
Orthologous Groups (KOG) (Tatusov et al. 2003), Kyoto Encyclopedia of Genes and Genomes (KEGG) (Kanehisa and Goto 2000), and The Arabidopsis Information Resource (TAIR) (Lamesch et al. 2011). Additionally, we annotated all proteins with protein domains from the Pfam-A (version 26) database (Finn et al. 2009) using the HMMER (version 3.0) program (Mistry et al. 2013) and an e-value cutoff of $1 \mathrm{e}-05$. Finally, genes were annotated with gene ontology (GO) terms for Arabidopsis thaliana orthologs (Lamesch et al. 2011) and with using Blast2GO software (Conesa and Götz 2008).

\section{RNA sequencing data analysis}

The $C$. sativus genome sequence and annotated genes were retrieved from the Phytozome (version 10) database (Goodstein et al. 2012). Sequence reads for each tissue sample were mapped to the reference genome (Gy14) using TopHat (version 2.0.12) (Kim et al. 2013), which is a splice-aware, short-read aligner. Transcript levels were subsequently quantified using the Flux Capacitor (version 1.6.1) program (Montgomery et al. 2010).

\section{Identification of differentially expressed genes}

Transcriptomes for the shoot apex and leaves were compared to analyze gene expression patterns. Transcripts that were expressed only in the shoot apex were compared to identify genes specifically involved in generative organ development and expressed in the third and fourth whorls of floral buds. Differentially expressed genes (DEGs) were detected using DESeq (Anders and Huber 2010), with an adjusted $p$ value cutoff of 0.05 and a fold change (FC) $\geq 4$ as the threshold. We defined genes with a normalized expression level below 10 as not expressed. We completed the following three comparisons: female $v s$ male; female $v s$ hermaphrodite; and male vs hermaphrodite. A cluster analysis was performed with the MeV 4.9.0 program (http://mev-tm4.sourceforge.net/svnro ot/mev-tm4/trunk) using Pearson correlation.

\section{Quantitative real-time PCR}

We designed qPCR primers for specific genes using the Primer3 (version 2.3.6) software and the C. sativus Gy14 (version 1.0) sequence. Reference genes were chosen based on the experimental results as previously described by Skarzyńska et al. (2016). Using the geNorm applet (Vandesompele et al. 2002), we selected two of the five tested reference genes for further analyses. Details regarding the qPCR primers and the corresponding amplicon lengths are provided in Table $\mathrm{S} 1$.

A qPCR assay was completed to verify RNA-seq data and compare transcript levels among the analyzed cucumber 
lines with different flower sex types. Of the genes identified by the bioinformatics analysis as being differentially expressed among the cucumber lines, 16 were analyzed by qPCR. All qPCR assays were completed using three biological replicates, with three technical replicates each. The cDNA included in the qPCR was reverse transcribed from $1 \mu \mathrm{g}$ total RNA and diluted (1:5). The qPCR assays were completed with $4 \mu \mathrm{L}$ cDNA, the Power SYBR ${ }^{\circledR}$ Green PCR Master Mix (Thermo Fisher Scientific, Waltham, MA, USA), and the Applied Biosystems 7500 Real-Time PCR System (Thermo Fisher Scientific, Waltham, MA, USA). A melting curve analysis was completed immediately after the qPCR. The mean amplification efficiency was calculated based on the linear regression for the slope of the regression line in the exponential phase with LinRegPCR (version 2015.3) (Ramakers et al. 2003). Relative expression levels were determined according to the $2^{-\Delta \Delta \mathrm{Ct}}$ method with RStudio and EasyqPCR from the Bioconductor software package (Pape 2012).

\section{Functional annotation and molecular networks}

A total of 310 DEGs were analyzed using MapMan 3.5.1 (Usadel et al. 2009). The cucumber mapping file was derived from the Phytozome (version 10) database. The STRING algorithm (version 10.5) (Szklarczyk et al. 2017), with A. thaliana as a model, was applied for an additional analysis of the possible interactions between the selected proteins. The confidence cutoff for the in silicopredicted molecular network was set at 0.70 . Furthermore, we used the Cytoscape stringAPP (version 3.4.0) to edit the layout of our map (Shannon et al. 2003). Nodes were grouped together with their neighbors based on their clustering coefficient for greater output clarity. Additionally, each node was color-coded based on the flower sex type in which the gene was most highly expressed (i.e., male, female, or hermaphrodite).

\section{Results and discussion}

To identify the genes responsible for early flower sex determination, we performed RNA-seq analysis. The sequenced transcriptomes were compared to identify DEGs associated with the formation of male, female, and hermaphroditic flowers. First, we compared leaf and shoot apex transcriptomes to distinguish between the vegetative organ- and generative organ-specific transcripts. Second, we compared the transcriptomes for the generative organs from the shoot apex to reveal the genes specifically expressed in different flower sex types. The general overview of our transcriptome analyses is presented in Fig. 1.

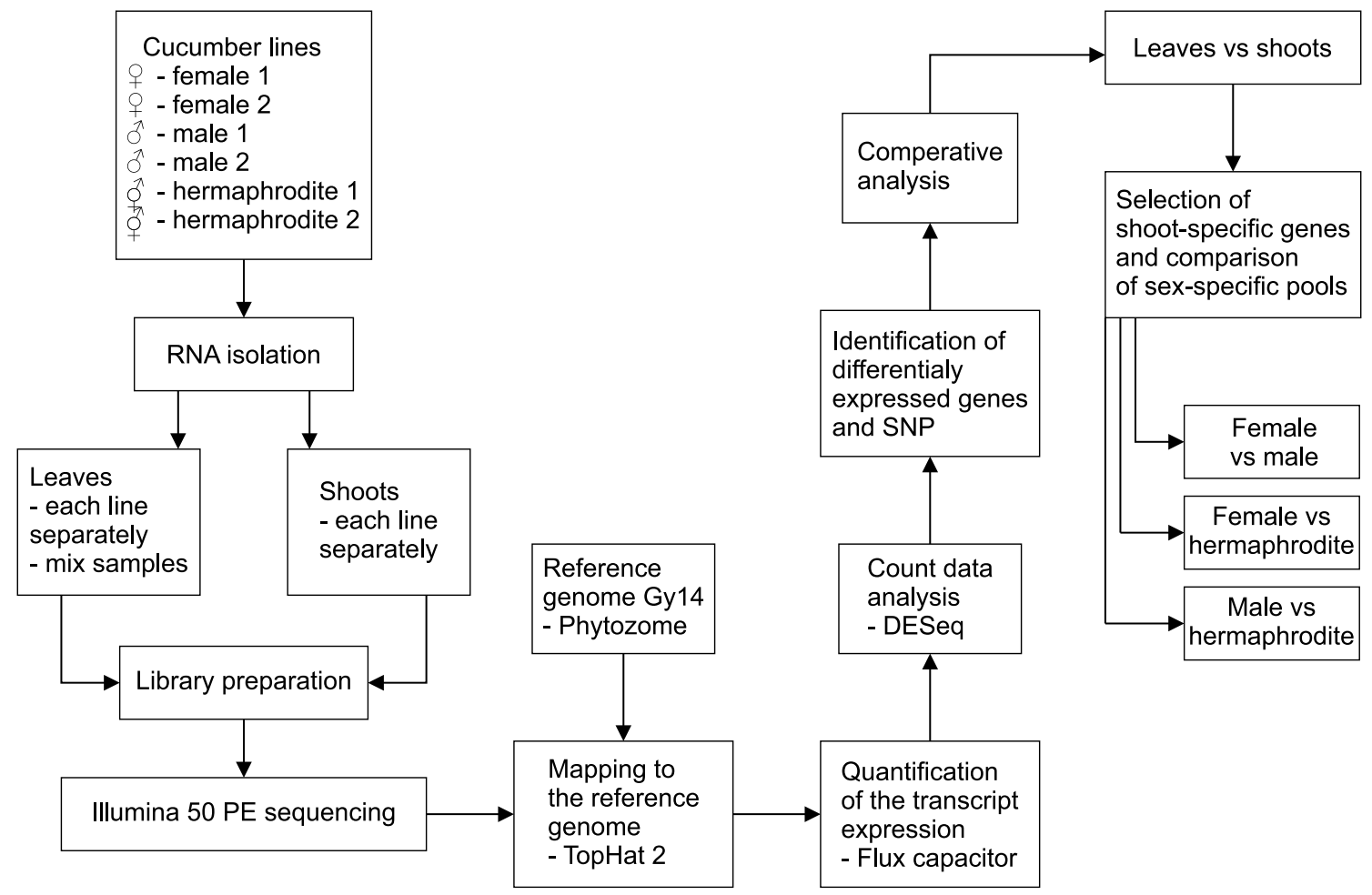

Fig. 1 Overview of the transcriptome comparisons 
Table 1 Mapping statistics for the short reads aligned to the reference genome

\begin{tabular}{llrrrrrr}
\hline Sample & \multicolumn{1}{l}{ Reads } & \multicolumn{1}{l}{ Aligned } & $(\%)$ & Aligned uniquely & $(\%)$ & Concordant pairs & $(\%)$ \\
\hline Leaves mix 1 & $174,302,526$ & $156,053,692$ & 89.53 & $146,824,160$ & 84.24 & $67,377,737$ & 77.31 \\
Leaves mix 2 & $100,610,456$ & $90,830,182$ & 90.28 & $85,189,347$ & 84.67 & $39,376,061$ & 78.27 \\
Male 1 & $176,901,600$ & $166,438,176$ & 94.09 & $162,745,831$ & 92.00 & $78,897,532$ & 89.20 \\
Male 2 & $161,712,846$ & $148,354,681$ & 91.74 & $143,956,991$ & 89.02 & $67,078,816$ & 82.96 \\
Female 1 & $156,338,944$ & $145,721,071$ & 93.21 & $142,613,880$ & 91.22 & $68,190,588$ & 87.23 \\
Female 2 & $159,498,702$ & $150,720,535$ & 94.50 & $147,119,433$ & 92.24 & $70,972,223$ & 88.99 \\
Hermaphrodite 1 & $148,861,648$ & $134,632,599$ & 90.44 & $130,806,274$ & 87.87 & $59,962,921$ & 80.56 \\
Hermaphrodite 2 & $140,273,124$ & $129,676,914$ & 92.45 & $126,846,024$ & 90.43 & $59,289,428$ & 84.53 \\
Control & $142,829,162$ & 520 & 0.00 & 393 & 0.00 & 26 & 0.00 \\
\hline
\end{tabular}

Table 2 Details regarding unigene annotations based on public databases

\begin{tabular}{lll}
\hline Public databases & Number of unigenes & $\begin{array}{l}\text { Percentage of } \\
\text { unigenes }(\%)\end{array}$ \\
\hline Phytozome & 30,364 & 100 \\
InterProScan & 25,628 & 84.4 \\
PFAM & 23,605 & 77.7 \\
Panther & 19,700 & 64.8 \\
KOG & 13,648 & 44.9 \\
KEGG & 5130 & 16.8 \\
GO & 17,924 & 59.1 \\
TAIR & 28,383 & 93.4 \\
\hline
\end{tabular}

\section{Sequencing, mapping, and gene annotation}

Short reads were aligned to the $C$. sativus Gy14 reference genome. We observed that $89.51-94.5 \%$ of the reads

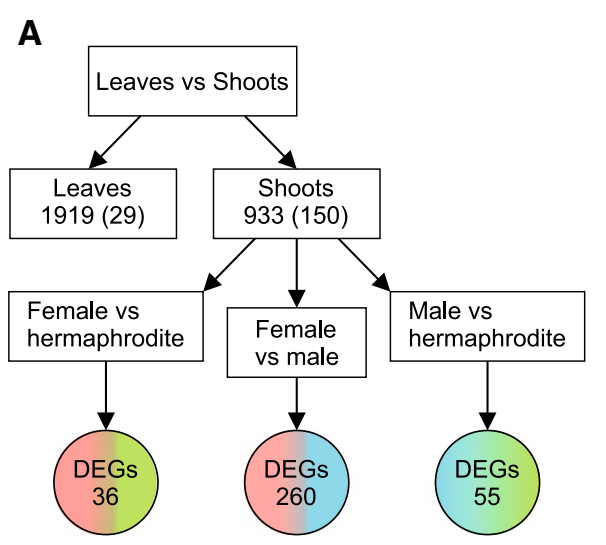

Fig. 2 Schematic representation of the completed analysis. a Comparison of leaf and shoot apex revealed genes with changed expression in vegetative and generative tissues. The number of genes exclusively expressed in sample was shown in brackets. The 933 DEGs that exhibited upregulated expression in tissues with small floral buds and generative organs were further analyzed to detect genes dif- were aligned to the genome, of which $84.24-92.24 \%$ of the reads were uniquely aligned (Table 1 ). These results suggested that high-quality sequencing libraries had been prepared. We observed that 29.5-48.6 Mb (15-24\%) of the C. sativus genome was expressed.

The unigenes were validated and annotated by aligning them to sequences from the following databases: Phytozome, InterProScan, Pfam, PANTHER, KOG, KEGG, and TAIR (Table 2, Table S2). A total of 30,364 mapped unigenes were matched to known genes in databases. Additionally, 25,628 C. sativus genes were annotated using InterProScan to obtain protein potential functions.

\section{Identification of differentially expressed genes}

We analyzed DEGs in four ways. First, we separated vegetative organ- and generative organ-specific transcripts by comparing the leaf and shoot apex transcriptomes. This comparison yielded 2852 DEGs (false discovery rate $<0.05$; fold

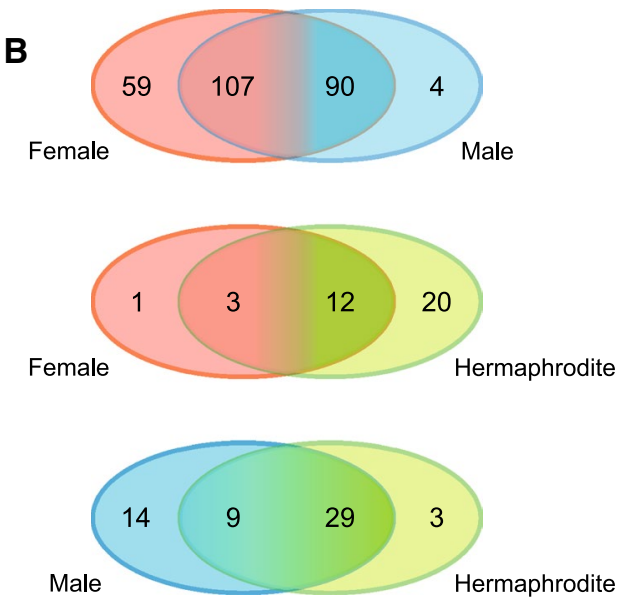

ferentially expressed among female, male, and hermaphroditic lines. b Venn diagrams of 310 sex-specific DEGs (in three comparisons: female vs male, female vs hermaphrodite, and male vs hermaphrodite) show number of genes with higher or exclusive expression in female, male or hermaphroditic line in each comparison 
Fig. 3 Heat map of differentially expressed genes in the leaf and shot apex tissues of male, female, and hermaphroditic lines. Gene expression levels are indicated at the top of the heat map, with red and green indicating upregulated and downregulated expression, respectively

change: 4), of which 933 were more highly expressed in the shoot apex and 150 of them were not expressed in vegetative tissue (i.e., shoot specific). Additionally, 1919 genes were more highly expressed in leaves, including 29 genes that were not expressed in the shoots (Fig. 2; Table S3).

Further, we analyzed DEGs with higher expression in the shoot apex based on the following three comparisons of flower sex types: female $v s$ male (FvM), female $v s$ hermaphrodite $(\mathrm{FvH})$, and male vs hermaphrodite $(\mathrm{MvH})$. We detected 310 DEGs as follows. A total of 260 DEGs were observed in the FvM comparison. Specifically, 111 genes were more highly expressed in female parts, including four genes that were not expressed in male parts. In contrast, 149 genes were more highly expressed in male parts, including 59 genes that were not expressed in female parts. The FvH comparison revealed 36 DEGs, three of which were more expressed in female parts and one gene that was not expressed in the hermaphrodite shoot apex. Additionally, 32 genes were more highly expressed in hermaphrodite parts, including 20 genes that were expressed exclusively in hermaphrodite samples. The $\mathrm{MvH}$ comparison detected 55 DEGs. Higher expression in male have shown 23 genes, 14 of which were only expressed in the male parts. Moreover, 31 genes were more highly expressed in hermaphrodite parts, three of which were expressed exclusively in hermaphrodite shoots. Quantity distributions of the 310 DEGs are presented in Fig. 2, while expression profiles are provided in Fig. 3 (Table S3).

\section{Confirmation of Illumina RNA-seq expression patterns by $q P C R$}

To validate the analysis of DEGs based on RNA-seq data, 16 randomly chosen genes were analyzed in a qPCR assay. The qPCR and RNA-seq data for these genes were compared (Fig. 4, Table S4). Highly reliable reference genes (CsCACS and $C s T I P 41$ ) were used to normalize the qPCR data according to the $2^{-\Delta \Delta C t}$ method. The qPCR and transcriptome analyses produced consistent expression profiles for 15 of the 16 analyzed genes (Cucsa.018,420, Cucsa.044950, Cucsa.048520, Cucsa.061700, Cucsa.074690, Cucsa.091510, Cucsa.098680, Cucsa.116470, Cucsa.133090, Cucsa.196810, Cucsa.196820, Cucsa.322240, Cucsa.212720, Cucsa.322240, and Cucsa.337660). The exception was Cucsa.120310. This lack of consistency may have occurred at least partly because of differences in the sensitivity of the techniques

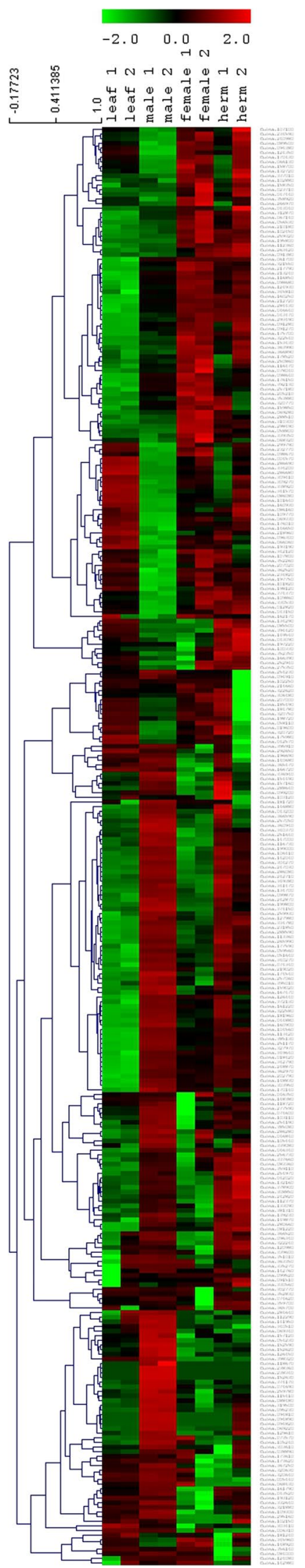



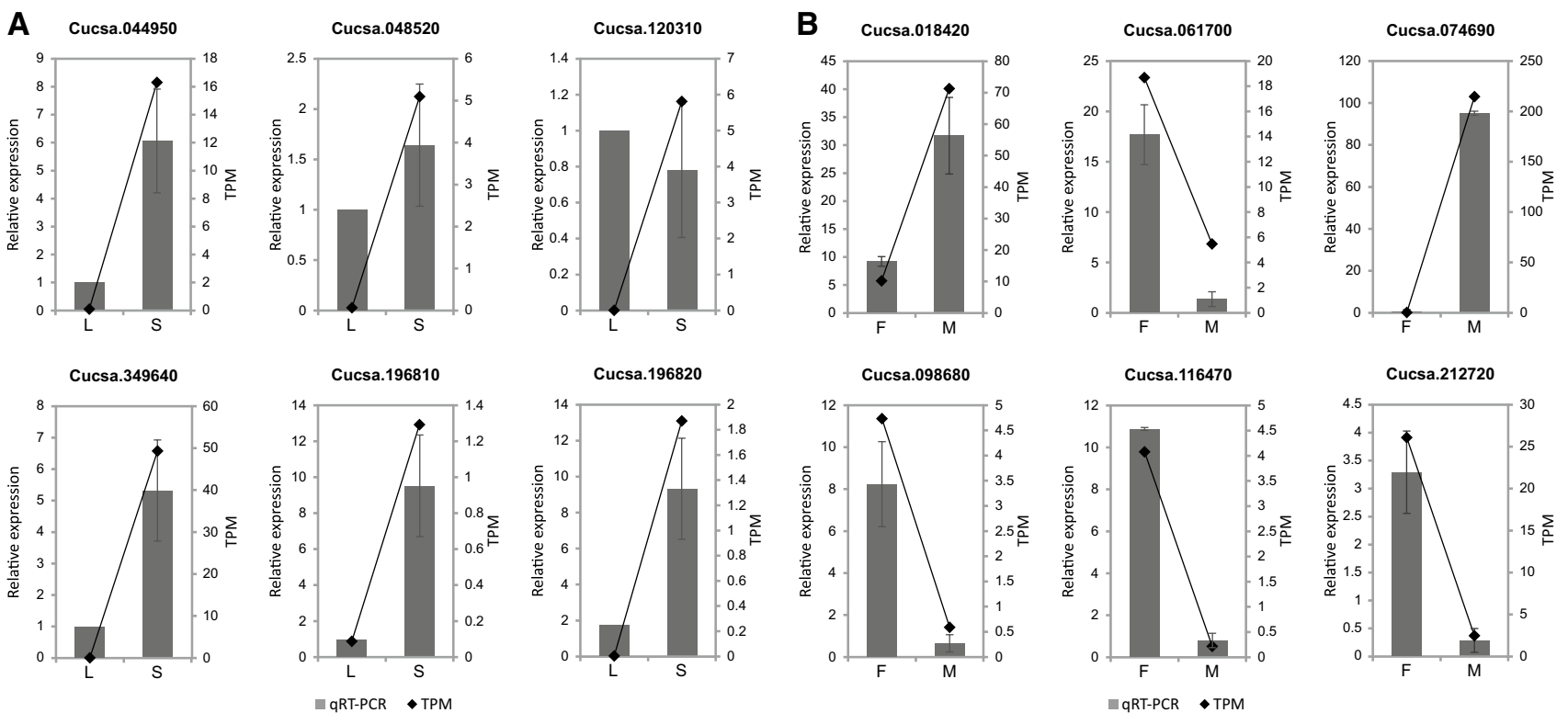

C
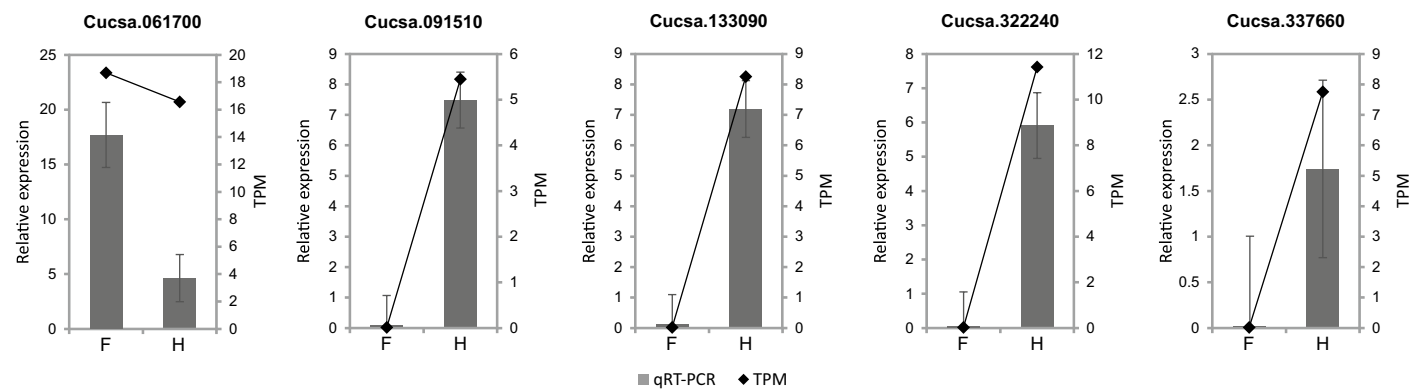

Fig. 4 Validation of DEG analyses by quantitative PCR [qPCR: relative expression; RNA-seq: transcripts per million (TPM)]. a Genes differentially expressed between vegetative (L, leaves) and generative

(S, shoots) tissues. b Genes differentially expressed between female (F) and male (M) shoots. c Genes differentially expressed between female $(\mathrm{F})$ and hermaphroditic $(\mathrm{H})$ shoots
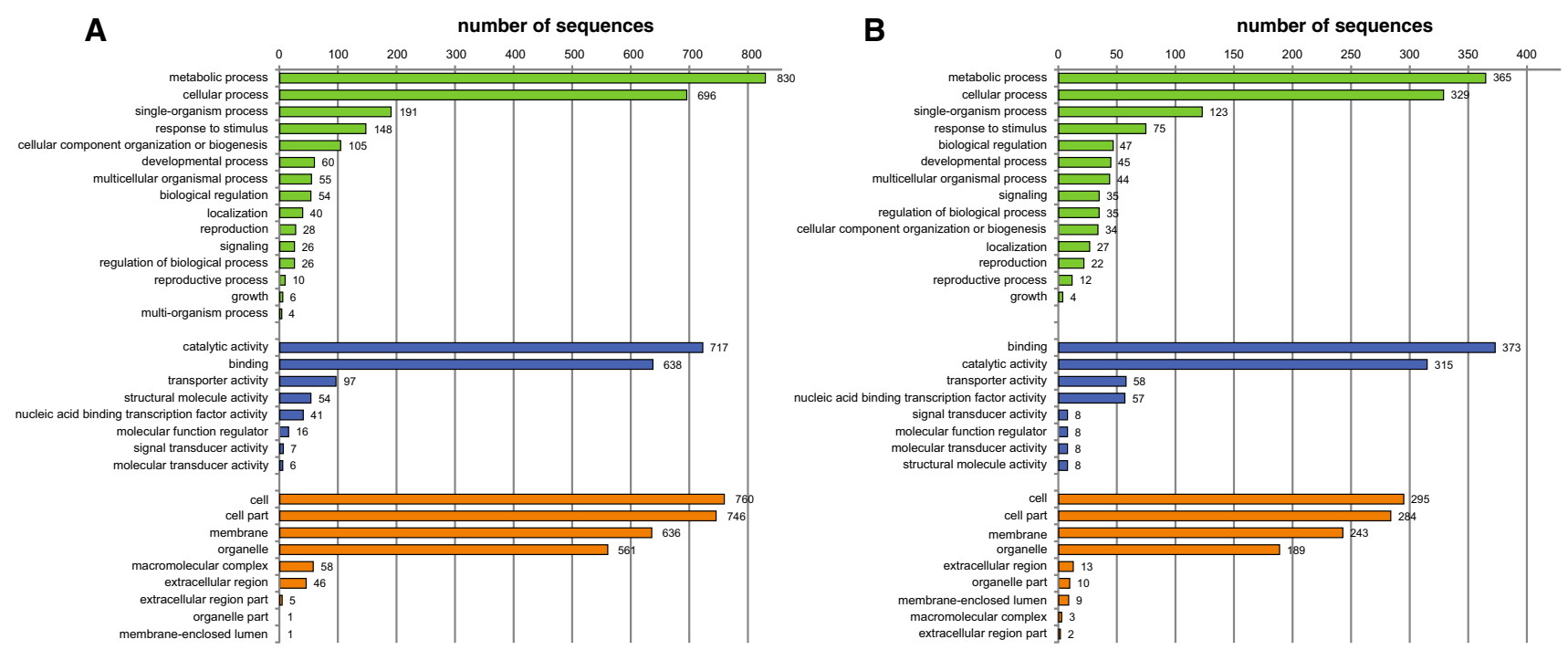

$\square$ biological process $\square$ molecular function $\square$ cellular compartment

Fig. 5 Histogram of GO analysis of DEGs detected in the comparison between leaves and the shoot apex. a Genes exhibiting upregulated expression in leaves (1919). b Genes exhibiting upregulated expression in the shoot apex (933) 
and algorithms. However, $94 \%$ of the analyzed DEG profiles were positively validated by qPCR.

\section{Functional annotation}

Selected genes were annotated with GO terms. Genes that exhibited upregulated expression in the shoot apex and leaves were assigned to functional categories using Blast2GO software. These genes were further classified using a set of plant-specific GO slims, and clustered into three main groups (biological process, molecular function, and cellular component). Details regarding the GO analysis of DEGs are provided in Fig. 5. Within the biological process category, metabolic process, cellular process, and single-organism process were among the most highly represented groups for the genes with upregulated expression in the shoot apex and leaves. Within the molecular function category, catalytic activity and binding were the most represented groups (Table S5).

\section{Functional annotation of sex-specific DEGs}

The 310 unigenes identified as sex-specific DEGs were annotated according to GO categories using the plantspecific GO slim. These DEGs were associated with 111 significantly enriched GO terms clustered into three main categories (Fig. 6). The most abundant GO terms in the biological process category were biosynthetic process, cellular nitrogen compound metabolic process, catabolic process, and carbohydrate metabolic process. In the molecular function category, ion binding and oxidoreductase activity were the most common GO terms. Meanwhile, in the cellular component category, cellular component and nucleus were the most abundant GO terms. Moreover, additional enriched GO terms were related to other processes and functions associated with flower development, including cell differentiation, flower development, and anatomical structure development (Table S6).

To visualize the dataset and further examine the genes related to sex determination, we completed a MapMan analysis, which determined the location and implied function for most of the 310 sex-specific DEGs. These genes were assigned to 22 out of 35 groups (Fig. 7, Table S7). The largest group included 47 genes, and was associated with RNA and the regulation of transcript levels (e.g., MADS box and homeobox). Another group (i.e., miscellaneous group) comprised 39 genes encoding various enzymes, such as oxidases, nitrilases, cytochrome P450, and peroxidases. A third group contained 27 genes encoding factors related to degradation, synthesis,

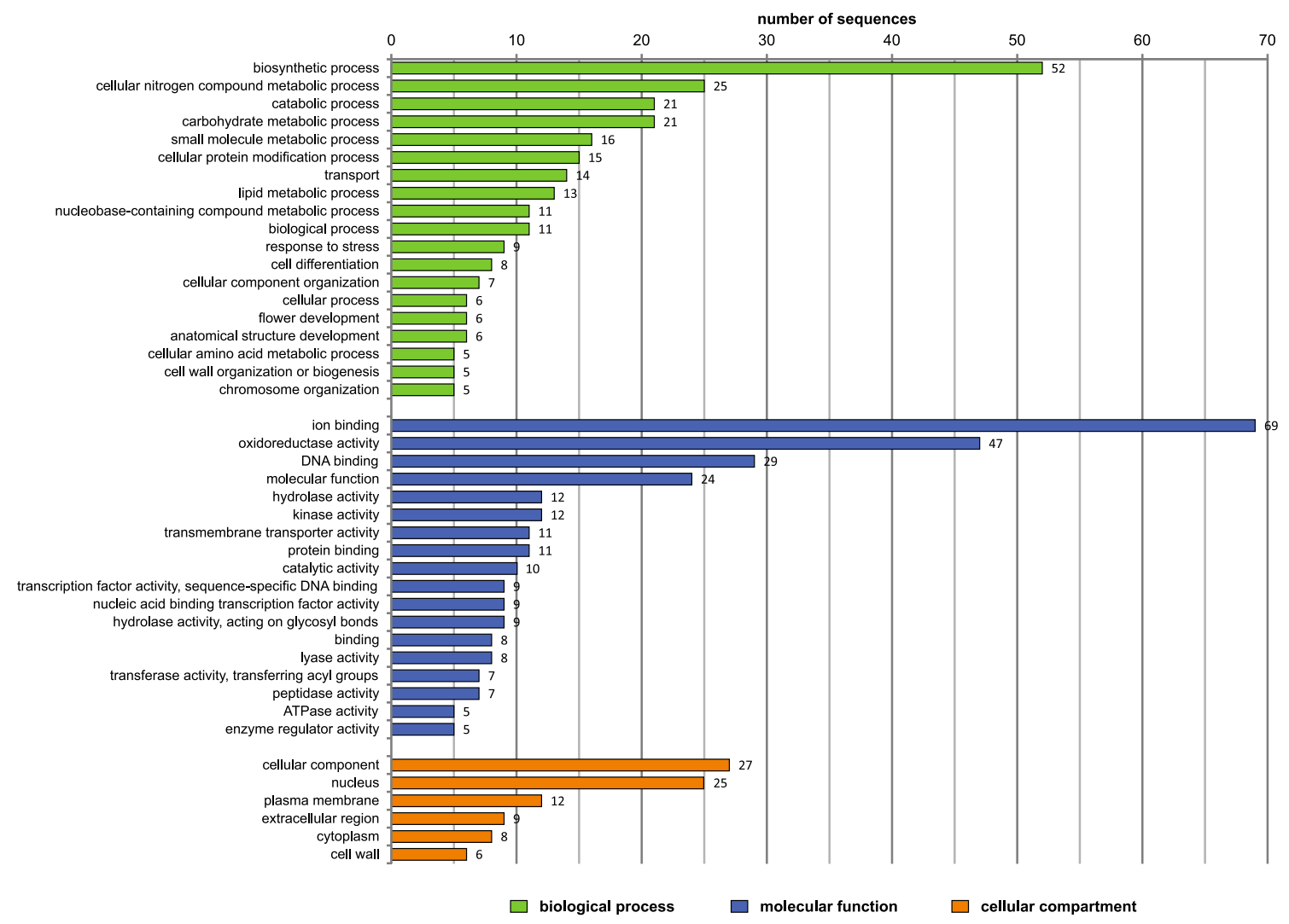

Fig. 6 Histogram of GO analysis of 310 sex-specific DEGs. The GO terms assigned to more than five genes are presented 
Fig. 7 MapMan analysis of 310 DEGs based on the following three comparisons: female $v s$ male, female $v s$ hermaphrodite, and male $v s$ hermaphrodite. Genes that were not differentially expressed in a specific comparison are indicated in white, genes upregulated in female are indicated in red, male are indicated in blue, and hermaphrodite are indicated in green

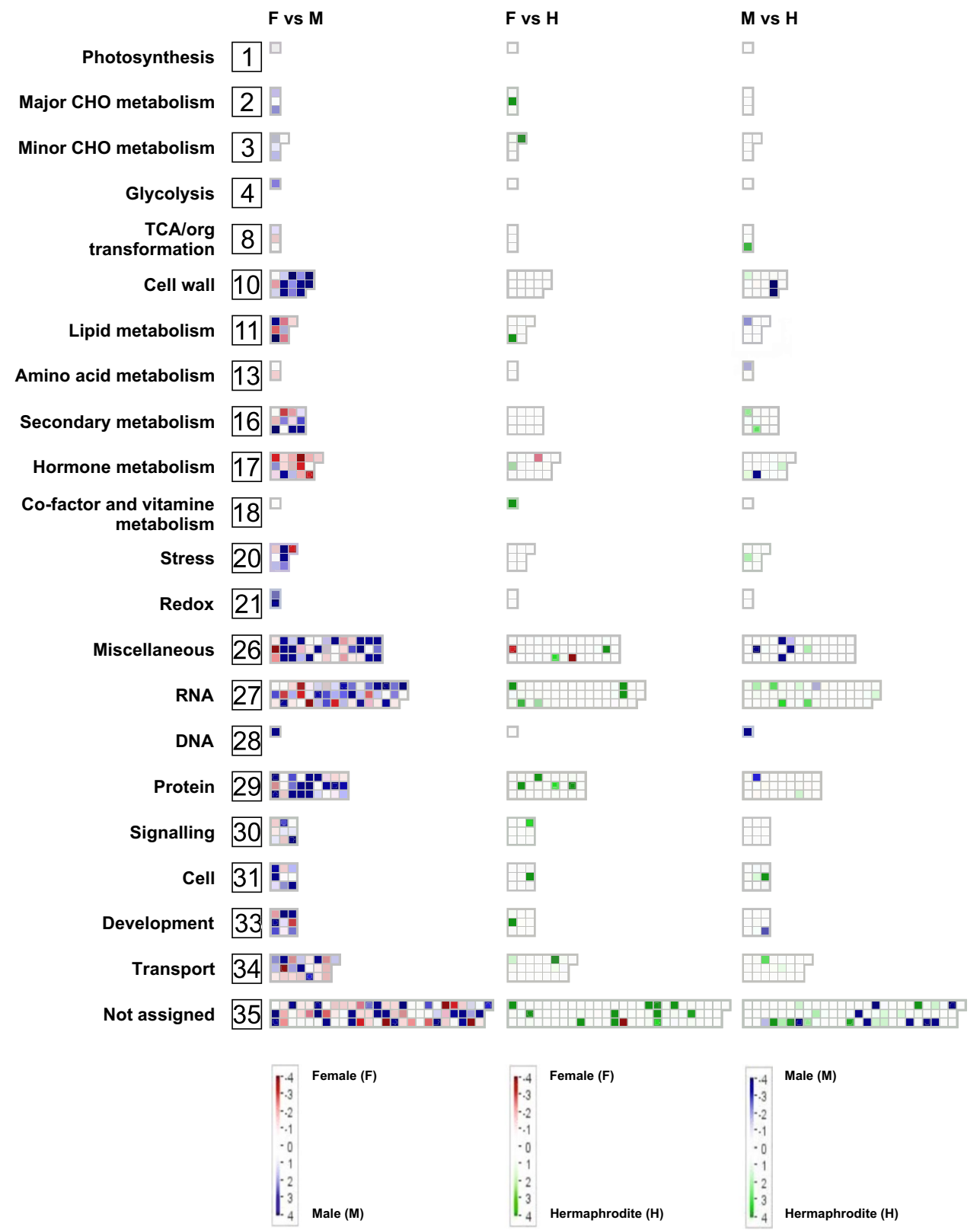

post-translational modifications, and protein interaction pathways. Other groups were associated with hormone metabolism, signaling, transport, secondary metabolism, or the cell wall. In male shoots, the genes with upregulated expression levels were associated with miscellaneous, protein, or cell wall groups. Meanwhile, in female shoots, the genes with upregulated expression levels were responsible for hormone metabolism, lipid metabolism, or transport. The groups with the fewest genes were related to photosynthesis, glycolysis, vitamin cofactor metabolism, DNA synthesis, and chromatin structure (Fig. 7).

\section{Bioinformatic modeling of interactions among proteins encoded by DEGs}

For the first time a molecular network of proteins connected to sex determination in cucumber was constructed based on the results of a STRING analysis (Fig. 8, Table S8). The network consisted of 269 nodes (each representing a protein) and 377 edges, with an average node degree of 2.79. Additionally, the average local clustering coefficient was 0.402 and the $\mathrm{p}$-value of the protein-protein interaction was $<1.0 \mathrm{e}-16$. These results imply the network content was based on non-random proteins. A total of 127 nodes were detected as a single component, while 18 nodes formed small two-component connections with mutual interactions. 


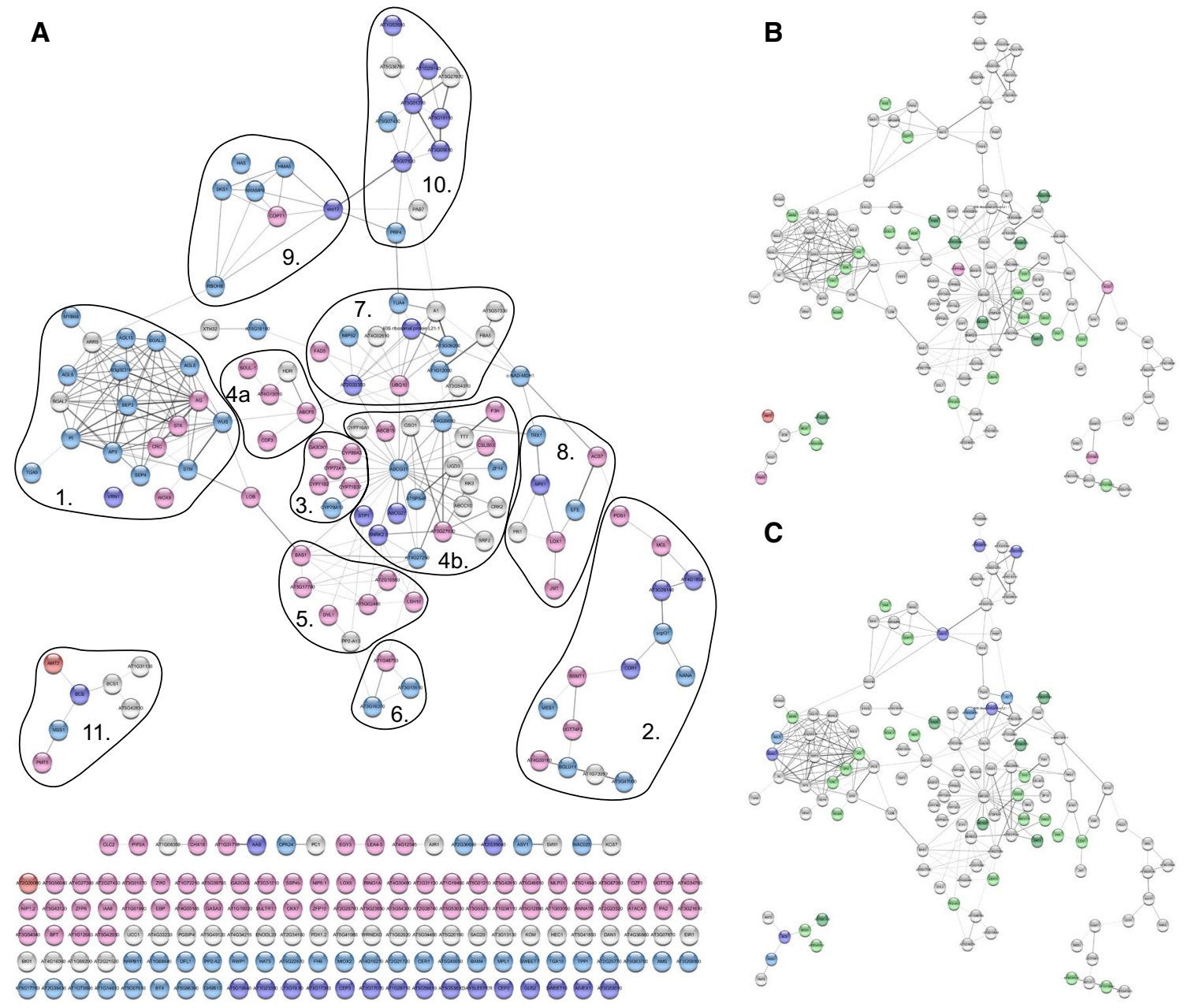

Fig. 8 The results of in silico study of STRING software for protein-protein interaction network for 310 sex-specific DEGs. There were gene expression differences between the female and male lines (a). Proteins in red were detected only in female lines, while proteins in light red were more abundant in the female shoot apex than in the male shoot apex. Similarly, proteins in blue were present only in male lines, while proteins in light blue were more abundant in the male shoot apex than in the female shoot apex. Nodes in gray were not differentially expressed between the male and female lines. The thickness of edges corresponds to the confidence of the protein connection (thicker line $=$ greater confidence in the connection). b Main network in the female $v s$ hermaphrodite comparison; Proteins in red were detected only in female lines, while proteins in light red were more abundant in the female shoot apex than in the hermaphroditic

Additionally, 117 nodes were included in the main molecular network, and seven nodes formed a smaller network. Protein-protein interactions were significantly enriched, indicating that the detected proteins in the STRING database interact more with each other than would be expected for a random set of similar-sized proteins encoded in a genome. This enrichment implies that the proteins are at least partially biologically related in a group. In this study, we distinguished the following 11 groups in the main molecular network (Fig. 8): (1) transcription factors that mediate the shoot apex. Similarly, proteins in green were present only in hermaphrodite lines, while proteins in light green were more abundant in the hermaphrodite shoot apex than in the female shoot apex. Nodes in gray were not differentially expressed between the hermaphrodite and female lines. c Main network in the male $v s$ hermaphrodite comparison. Proteins in blue were detected only in male lines, while proteins in light blue were more abundant in the male shoot apex than in the hermaphroditic shoot apex. Similarly, proteins in green were present only in hermaphrodite lines, while proteins in light green were more abundant in the hermaphrodite shoot apex than in the male shoot apex. Nodes in gray were not differentially expressed between the hermaphrodite and male lines. Networks were prepared using the STRING program and then visualized with Cytoscape

transition from an inflorescence meristem to a floral meristem, floral meristem development, and regulation of floral organ identity; (2) enzymes (transferase, peptidase, esterase, and protease); (3) cytochromes; (4a) and (4b) represent the central nodes with ATP-binding transporters that use the energy from the binding and hydrolysis of ATP to transport various substrates across cellular membranes, thereby regulating many processes; (5) proteins associated with brassinosteroids and the regulation of development via ubiquitination-related molecules; (6) lipid metabolism; 
(7) proteins related to ubiquitination processes; (8) proteins from the ethylene and jasmonic acid signaling pathways; (9) metal ion binding; (10) pectin catabolic processes related to pollen maturation and the flowering stage; and (11) proteins related to ion transport, sugar metabolism, and programmed cell death (PCD).

The molecular network described herein may clarify the possible protein interactions mediating processes influencing sex determination in cucumber. To date, protein-protein interactions occurring during flower development have not been established because of the complexity of the relevant processes. Thus, an important part of flower morphogenesis studies involves elucidating the complex processes that occur during the formation of the floral meristem and organ primordia. The first event during floral development is the initiation of apical meristem cell differentiation, resulting in the production of a floral meristem. At the moment of differentiation, it is critical that the correct organs are created at the required locations and the duration of cell proliferation is appropriate. Furthermore, specific cells form the floral organ primordia, after which the flower bud starts to develop. Typically, the most intensive growth takes place in the lateral cells, from which sepals develop in the first whorl. Cells then differentiate into the petals of the second whorl. The stamen and pistil primordia appear in the third and fourth whorls, and grow very slowly. The primordia of generative organs in the third and fourth whorls have a different fate. Because each organ occupies a distinct whorl, cells in the shoot apex must assume the correct organization and position. It remains unclear which processes and mechanisms define the cell fate and determine the flower organ identity and sex (Kim et al. 2000). However, a very complex mechanism involving many genes is almost certainly required. To identify appropriate links between sex determination and flower morphogenesis in cucumber, we manually curated the in silico functional analyses (Table S9). We revealed a novel regulatory mechanism that provides new insights into flower development (Fig. 9).

\section{Transcription factors}

Transcription factors (TF) are important regulators of cellular processes in plant development. One group of TF, those involved in floral organ identity determination, is plant MADS-box. Analysis of homeotic floral mutants resulted in the formulation of a genetic model, named the ABC model (Coen and Meyerowitz 1991) and later was expanded to include classes D and E. This model, that explains how the combined functions of classes of genes determine the identity of the four flower organs. The development of sex-specific organs relies on the combinatorial and differential expression of such homeotic genes over time and space (Guo et al. 2015). Based on the quartet model, the A- and E-class complex [APETALA1 (AP1)- SEPALLATA (SEP)] specify the sepal identity; A-, B- and E-class proteins [AP1-SEP-AP3-PISTILLATA (PI)] specify petals; the B-, C- and E-class complex [AGAMOUS (AG)-SEP-AP3-PI] specify stamens; the C- and E-class complex (AG-SEP) specify carpels; and the D- and E-class complex [SEEDSTICK (STK)-SEP] specify ovules (Bowman et al. 2012; Guo et al. 2015). In this study, we identified genes related to transcription factors (10\%) (Fig. 8; Tables 3, S3, and S9), including AGAMOUS (Cucsa.251170, Cucsa.202790, Cucsa.362970, Cucsa.174540, Cucsa.248870, and Cucsa.212720), SEPALLATA (Cucsa.018420, Cucsa.327970, and Cucsa.349640), SEEDSTICK (Cucsa.061700), PISTILLATA (Cucsa.018420), and APETALA 3 (Cucsa.342790), which are expressed according to the MADS-box rules.

We also detected TF like HAT5 (Cucsa.159020), which reportedly encodes an essential protein for the proper development of basal and lateral organ boundaries (Rutjens et al. 2009), and two genes with a WUSCHEL (WUS) domain female-specific homeobox-3 (HB-3)/WOX 9 (Cucsa.046640) and male-specific WUS (Cucsa.043520). The WUSCHEL promotes stem cell proliferation. Based on literature reports, WUS and AG interact with each other. The initial expression of $A G$ is activated by the WUS, but the accumulation of AG and also involvement of other proteins leads to WUS repression (Liu et al. 2011) what influence on terminating floral stem activities (Guo et al. 2015).

KNOX STM SHOOT MERISTEMLESS (Cucsa.148830) encodes a protein belonging to the KNOTTED1-like TALE (KNAT) class I family of transcription factors and could influence meristem activity. The KN1-related homeobox KNOX proteins may suppress cell differentiation (Kerstetter et al. 1997) and also repress gibberellic acid (GA) biosynthesis, which in turn may induce cell differentiation (Hay et al. 2002). The LOB protein (Cucsa.098680), which appears to be a female-specific protein, contributes to pollen development, as reported by $\mathrm{Xu}$ (Xu et al. 2016). Moreover, in other study, it was proven that LOB interacts with KNOX proteins to maintain stem cell identity (Rast and Simon 2012) and also negatively regulates brassinosteroid accumulation (Bell et al. 2012).

We identified other transcription factors $(5 \%)$ that regulate various developmental processes, but any relationships with sex determination in cucumber have not been established till now. Some of these transcription factors (e.g., belonging to the large NAC domain family containing protein or bHLH protein family) were also detected in an earlier study devoted to sex expression in gynoecious and hermaphroditic cucumber lines (Guo et al. 2010). Transcription factors with typical binding motifs, such as bZIP, MYB, and a zinc finger, are inducible by many signals (Ambawat et al. 2013). 


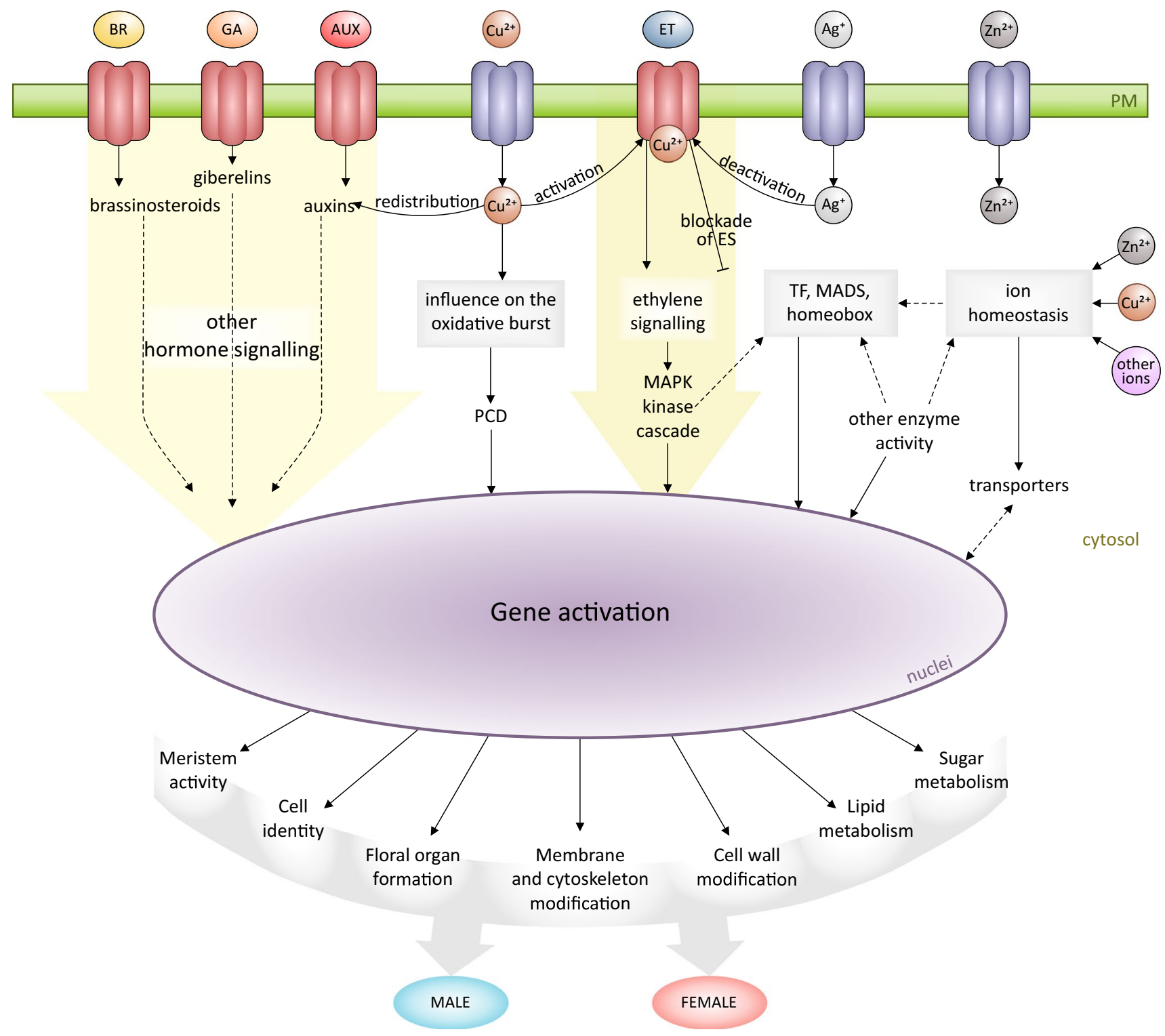

Fig. 9 Proposed hypothetical model of the regulatory networks associated with sex determination in cucumber

The factors responsible for floral organ identity (e.g., homeobox) and other transcription factors control the expression of many genes involved in diverse metabolic processes, including responses to different hormones such as ethylene (Han et al. 2016), cytokinins, auxins, gibberellins, and jasmonic acid (Thomson et al. 2017). These hormones also mediate various activities during floral bud development, starting from meristematic activity, as well as organ pattern formation and maturation (Chandler 2011).

\section{Hormones}

We identified genes $(6.7 \%)$ correlated with the transduction or synthesis of hormones like auxins, cytokinins, ethylene (promotes femaleness), gibberellins (promotes maleness), abscisic acid (ABA), and brassinosteroids (Tables 4, S3, S9).

Ethylene is important for the development of female flowers. The mechanism by which ethylene triggers sex determination in cucumber has been extensively studied. The first step of the ethylene signaling cascade involves the perception of the hormone by a family of ethylene receptors (ETR1, ETR2, ERS1, ERS2, and EIN4) and then the signal processing by downstream proteins as follows: Ethylene receptors $\rightarrow$ CTR $\rightarrow$ EIN2 $\rightarrow$ EIN3/EIN3-like $\rightarrow$ ERF $\rightarrow$ response (Hubert et al. 2014). We identified several ethylene-related genes that were highly expressed in female lines, and were correlated with ethylene biosynthesis. These genes included those encoding methionine (Cucsa.322540), an 
Table 3 Transcription factors encoded by the DEGs

\begin{tabular}{lllrc}
\hline Comparison & Gene ID & Description & Log2FC & Adj $p$ value \\
\hline Female FvM & Cucsa.366890 & Basic helix-loop-helix (bHLH) DNA-binding & -2.85 & $3,95 \mathrm{E}-02$ \\
Female FvM & Cucsa.284430 & Plant-specific transcription factor YABBY & -3.57 & $2,11 \mathrm{E}-36$ \\
Female FvM & Cucsa.160250 & Basic helix-loop-helix (bHLH) DNA-binding & -1.14 & $2.42 \mathrm{E}-03$ \\
Female FvM & Cucsa.240980 & Basic-leucine zipper (bZIP) TF & -1.02 & $8.97 \mathrm{E}-03$ \\
Female FvM & Cucsa.175980 & PAR1 protein & -1.56 & $1.78 \mathrm{E}-02$ \\
Female FvM & Cucsa.160930 & transcription factor-related & -1.14 & $2.65 \mathrm{E}-02$ \\
Male FvM & Cucsa.352830 & PHD finger transcription factor, putative & 6.58 & $2.04 \mathrm{E}-05$ \\
Male FvM & Cucsa.126450 & NAC domain-containing protein 25 & 2.54 & $9.37 \mathrm{E}-06$ \\
Male FvM & Cucsa.074600 & NAC domain-containing protein 2 & 2.87 & $7.59 \mathrm{E}-05$ \\
Male FvM & Cucsa.366520 & AP2/B3-like transcriptional factor & 6.70 & $1.85 \mathrm{E}-10$ \\
Male FvM & Cucsa.366590 & AP2/B3-like transcriptional factor & 1.54 & $1.80 \mathrm{E}-02$ \\
Male FvM & Cucsa.265990 & basic helix-loop-helix (bHLH) DNA-binding & 1.96 & $2.34 \mathrm{E}-03$ \\
Male FvM & Cucsa.199800 & bZIP transcription factor family protein & 2.49 & $1.42 \mathrm{E}-13$ \\
Male FvM & Cucsa.242870 & bZIP transcription factor family protein & 3.18 & $2.97 \mathrm{E}-08$ \\
Male FvM & Cucsa.385130 & bZIP transcription factor family protein & 1.50 & $5.10 \mathrm{E}-03$ \\
Male FvM & Cucsa.288590 & myb domain protein 68 & 3.84 & $2.18 \mathrm{E}-15$ \\
\hline
\end{tabular}

Table 4 Differentially expressed genes associated with hormone signaling

\begin{tabular}{|c|c|c|c|c|c|}
\hline Comparison & Gene ID & Description & Hormone & $\log 2 \mathrm{FC}$ & Adj $p$ value \\
\hline Female FvM & Сисsa.069330 & Protein phosphatase 2C & $\mathrm{ABA}$ & -1.60 & $4.88 \mathrm{E}-03$ \\
\hline Female FvM & Cucsa.043470 & SAUR-like auxin-responsive & Auxin & -1.33 & $1.03 \mathrm{E}-04$ \\
\hline Female FvM & Cucsa. 178520 & Auxin efflux & Auxin & -3.12 & $9.86 \mathrm{E}-03$ \\
\hline Female FvM & Cucsa.320720 & Auxin-Induced & Auxin & -1.45 & $3.52 \mathrm{E}-03$ \\
\hline Female FvM & Cucsa.310300 & Indoleacetic acid-induced & Auxin & -1.67 & $7.42 \mathrm{E}-08$ \\
\hline Female FvM & Cucsa. 232770 & BRI1 kinase inhibitor 1 & Brassinosteroids & -1.28 & $2.66 \mathrm{E}-02$ \\
\hline Female FvM & Сucsa.299790 & Cytokinin oxidase 7 & Cytokines & -1.21 & $8.98 \mathrm{E}-03$ \\
\hline Female FvM & Cucsa.234590 & S-adenosyl-L-methionine methyltransferases & Ethylene & -3.33 & $2.75 \mathrm{E}-02$ \\
\hline Female FvM & Сисsa.298490 & ethylene-dependent gravitropism-deficient & Ethylene & -1.15 & $4.02 \mathrm{E}-03$ \\
\hline Female FvM & Cucsa.069280 & Ethylene-responsive element binding & Ethylene & -1.09 & $1.79 \mathrm{E}-03$ \\
\hline Female FvM & Сисsa.322540 & Methionine gamma-lyase & Ethylene & -1.47 & $3.28 \mathrm{E}-06$ \\
\hline Female FvM & Cucsa.288510 & 1-Aminocyclopropane-1-carboxylate synthase 7 & Ethylene & -5.04 & $1.03 \mathrm{E}-12$ \\
\hline Female FvM & Cucsa.086080 & Gibberellin 2-oxidase 8 & Gibberellin & -1.73 & $9.03 \mathrm{E}-03$ \\
\hline Female FvM & Cucsa.004570 & Gibberellin 3-oxidase 1 & Gibberellin & -1.63 & $3.64 \mathrm{E}-03$ \\
\hline Female FvM & Cucsa.159850 & GAST1 protein homolog 3 & Gibberellin & -3.11 & $1.39 \mathrm{E}-03$ \\
\hline Herma FvH & Cucsa.359110 & Pyridoxine biosynthesis & Auxin & 8.17 & $1.73 \mathrm{E}-12$ \\
\hline Herma FvH & Cucsa.132160 & Tetratricopeptide repeat (TPR)-like & Ethylene & 3.64 & $2.65 \mathrm{E}-02$ \\
\hline Herma MvH & Cucsa.330530 & Response regulator 9 & Gibberellin & 2.07 & $2.22 \mathrm{E}-03$ \\
\hline Male FvM & Cисsa.330560 & TRAF-like family protein & $\mathrm{ABA}$ & Inf & $4.66 \mathrm{E}-03$ \\
\hline Male FvM & Сисsa.059560 & Auxin-responsive GH3 & Auxin & 2.28 & $5.89 \mathrm{E}-05$ \\
\hline Male FvM & Cucsa.044880 & Ethylene-forming enzyme & Ethylene & 1.73 & $3.86 \mathrm{E}-07$ \\
\hline
\end{tabular}

S-adenosyl-L-methionine-dependent methyltransferase superfamily protein (Cucsa.234590), and 1-aminocyclopropane-1-carboxylate synthase 7 (Cucsa.288510). The expression of these genes was also correlated with the expression of genes mediating ethylene responses, such as the ethylene-dependent gravitropism-deficient protein (Cucsa.298490), ethylene-responsive element-binding protein (Cucsa.069280), and the tetratricopeptide repeat-like superfamily protein (Cucsa.132160). The only gene that was more highly expressed in male lines than in female lines was Cucsa.044880, which encodes an ethylene-forming enzyme, 1-aminocyclopropane-1-carboxylate oxidase 4. Interestingly, two genes correlated with the biosynthesis of methionine, which is the main amino acid used for ethylene synthesis, 
encode MTO1 pyridoxal phosphate-dependent transferases (Hacham et al. 2013). The expression of these two genes was differentially regulated in male (Cucsa.166720) and female (Cucsa.392130) cucumber lines. The high expression levels for the ethylene-related genes in the female lines are consistent with the findings of a previous study on sex determination in cucumber that proved that the ethylene contents and ACS expression levels are higher in female lines than in male or hermaphroditic lines (Boualem et al. 2008, 2015; Li et al. 2009; Mibus and Tatlioglu 2004; Trebitsh et al. 1997).

Auxin effects induce femaleness by increasing the ethylene level (Yin and Quinn 1995). In this study, with the exception of one male-specific gene (Cucsa.059560), all of the identified genes were highly expressed in female lines and encode proteins that induce or transduce auxin signals. These observations are consistent with published data. Probably, female plants produce relatively large amounts of auxin and transducers, which are needed to enhance the production of female flowers. The cytokinin oxidase $C K X 7$ gene (Cucsa.299790) is also highly expressed in females. How these hormones influence sex determination in plants has not been determined, but will be investigated in our future studies.

Gibberellins also affect sex differentiation in cucumber, but unlike auxin and ethylene, they influence the formation of male flowers. Treating cucumber plants with exogenous GA inhibits ethylene biosynthesis by suppressing CsACS1G expression. In females, gibberellin-related genes are highly expressed. These genes include those encoding oxidases (Cucsa.004570 and Cucsa.086080), response regulators (Cucsa.330530), and the gibberellic acid stimulated-like protein (Cucsa.159850). The involvement of GA in cucumber flower formation was also described by Zhang et al. (2014). They identified CsGAMYBI as a positive regulator of the GA signaling pathway in cucumber, which presumably promotes male flower development and inhibits ethylene production and the formation of female flowers.

There is no clear connection between flower formation and ABA or brassinosteroids. The genes encoding ABArelated protein phosphatase $2 \mathrm{C}$ were revealed to be differentially expressed (Pawełkowicz et al. 2016b). These observations were confirmed by our RNA-seq data. Additionally, the female-specific protein phosphatase 2C (Cucsa.069330) is a negative regulator of $\mathrm{ABA}$ and the tumor necrosis factor receptor-associated factor (Cucsa.330560), which is a positive component of the ABA signaling pathway (Bao et al. 2014). Furthermore, a brassinosteroid-correlated gene (Cucsa.232770) encoding BRI1 kinase inhibitor 1 was highly expressed in females. The above mentioned genes may modulate signal transduction pathways and change the sensitivity of female tissues to certain hormones. Plant hormones and sex determination are not highly correlated, but the crosstalk involving a hormone-signaling cascade may affect cucumber flower formation. Ethylene eliminates the effects of the other hormones and is a major sex-regulating factor.

\section{Metal ions}

The relationship between metal ion homeostasis and ethylene signaling has been revealed (Hirayama and Alonso 2000). In this study, we determined that $8.7 \%$ of the DEGs (Tables 5, S3, S9) are correlated with metal ion processes, especially those involving copper (3.2\%) (Fig. 8 bin 9) and zinc (2.9\%).

There is biochemical evidence indicating that copper is an important for plant growth due to its contribution in many processes including oxidative stress responses, cell wall metabolism (Yruela 2005), auxin redistribution (Yuan et al. 2013), and ethylene perception and signaling (Hirayama and Alonso 2000). Copper ions induce the ethylene biosynthesis pathway, by upregulating the expression of ACS genes (Mao et al. 2015; Wang et al. 2002; Yang and Hoffman 1984; Zhang et al. 2017), which are referred to as sex genes in cucumber. A previous investigation confirmed that a $\mathrm{CuSO}_{4}$ treatment promotes the accumulation of reactive oxygen species and callose deposition in the cell wall, while also activating MAP kinase signaling (Liu et al. 2015). Several genes (Cucsa.112290, Cucsa.152590, Cucsa.152620, Cucsa.152630, and Cucsa.251640) that were highly expressed in male lines encode glycoproteins that are structurally related to multiple copper oxidases (e.g., SKU5). Previous studies by Loraines's group revealed that $S K U$ is highly expressed in mature pollen grains, with the encoded protein localized in the plasma membrane and cell wall (Loraine et al. 2013; Wang et al. 2008). Our results suggest that SKU5 may have a regulatory function during cucumber flower development via its effects on cell walls as well as during pollen formation. Other DEGs related to copper, encoded blue copper proteins (BCPs) (Table 5). According to the literature, these proteins may participate in electron transfers, affect redox reactions, and influence cell wall formation in plants (Nersissian et al. 1998), while functioning with other molecules (e.g., cytochromes) (Printz et al. 2016). In a recent study, type 1 BCPs were observed to be secreted from the pistil to guide the pollen tube and grain toward the pistil (Rhee et al. 2015). These BCPs are reportedly male sterility factors in some cotton lines (Suzuki et al. 2013).

Little is known about copper uptake and transport in plants. In this study, we identified genes encoding possible copper transporters (Cucsa.146650, Cucsa.177590, Cucsa.367250, and Cucsa.177590). Copper influences ethylene signaling because ethylene receptors are copper dependent (Alonso et al. 1999; Hirayama and Alonso 2000; Rodriguez et al. 1999). Ethylene, which binds to receptor, requires copper as a cofactor. Interestingly, ethylene receptor 
Table 5 Differentially expressed genes related to hormone signaling

\begin{tabular}{|c|c|c|c|c|c|}
\hline Comaprison & Gene ID & Description & Specifity & $\log 2 \mathrm{FC}$ & Adj $p$ value \\
\hline Female FvM & Cucsa. 146650 & Copper transporter 1 & Copper & -2.31 & $4.75 \mathrm{E}-03$ \\
\hline Female FvM & Cucsa. 185490 & Copper amine oxidase & Copper & -1.74 & $2.16 \mathrm{E}-06$ \\
\hline Female FvM & Cucsa.176010 & SOUL heme-binding & Ion binding & -1.43 & $3.64 \mathrm{E}-03$ \\
\hline Female FvM & Cucsa.162170 & Ammonium transporter 2 & Ion binding & -4.81 & $4.01 \mathrm{E}-02$ \\
\hline Female FvM & Cucsa. 312870 & Transcription factor jumonji & Zinc & -1.03 & $9.86 \mathrm{E}-03$ \\
\hline Female FvM & Cucsa. 116850 & $\mathrm{CCCH}$-type zinc finger & Zinc & -0.87 & $4.48 \mathrm{E}-02$ \\
\hline Female FvM & Cucsa.078040 & Zinc-binding dehydrogenase & Zinc & -0.98 & $1.46 \mathrm{E}-02$ \\
\hline Female FvM & Cucsa. 205210 & Zinc finger protein 6 & Zinc & -1.38 & $2.24 \mathrm{E}-04$ \\
\hline Female FvM & Сucsa. 175700 & Zinc finger protein 10 & Zinc & -3.39 & $4.31 \mathrm{E}-09$ \\
\hline Herma FvH & Cucsa. 112370 & Uclacyanin 1 & Copper & 4.63 & $8.54 \mathrm{E}-05$ \\
\hline Herma FvH & Cucsa. 337660 & Werner syndrome-like exonuclease & Ion binding & 9.72 & $8.69 \mathrm{E}-22$ \\
\hline Herma FvH & Cucsa. 322240 & RING/FYVE/PHD zinc finger & Zinc & 10.35 & $1.57 \mathrm{E}-09$ \\
\hline Herma FvH & Cucsa.280660 & Zinc finger C-x8-C-x5-C-x3-H type & Zinc & 2.27 & $5.26 \mathrm{E}-03$ \\
\hline Herma MvH & Cucsa. 109860 & 4-Hydroxy-3-methylbut-2-enyl diphosphate reductase & Ion binding & 2.27 & $5.76 \mathrm{E}-03$ \\
\hline Male FvM & Cucsa. 152590 & SKU5 similar 12 & Copper & 7.69 & $1.47 \mathrm{E}-03$ \\
\hline Male FvM & Cucsa. 105440 & Blue-copper-binding protein & Copper & 8.12 & $2.37 \mathrm{E}-03$ \\
\hline Male FvM & Cucsa. 177590 & NRAMP metal ion transporter 6 & Copper & 2.08 & $1.47 \mathrm{E}-03$ \\
\hline Male FvM & Cucsa.112290 & SKU5 similar 12 & Copper & 5.24 & $4.07 \mathrm{E}-02$ \\
\hline Male FvM & Cucsa. 152620 & SKU5 similar 12 & Copper & 6.65 & $1.46 \mathrm{E}-02$ \\
\hline Male FvM & Cucsa. 152630 & SKU5 similar 12 & Copper & Inf & $1.39 \mathrm{E}-03$ \\
\hline Male FvM & Cucsa. 251640 & SKU5 similar 1 & Copper & 1.77 & $4.03 \mathrm{E}-05$ \\
\hline Male FvM & Cucsa. 170140 & SNF1-related protein kinase 2.5 & Ion binding & Inf & $2.60 \mathrm{E}-02$ \\
\hline Male FvM & Cucsa.319500 & subtilase family protein & Ion binding & 4.86 & $4.23 \mathrm{E}-02$ \\
\hline Male FvM & Cucsa. 398320 & 2-Oxoglutarate Fe(II)-dependent oxygenase & Ion binding & 5.71 & $4.79 \mathrm{E}-09$ \\
\hline Male FvM & Cucsa. 367250 & Heavy metal atpase 5 & Ion binding & 1.59 & $4.23 \mathrm{E}-02$ \\
\hline Male FvM & Cucsa. 173610 & BED zinc finger & Zinc & Inf & $3.63 \mathrm{E}-03$ \\
\hline Male FvM & Cucsa.259930 & Zinc ion binding; DNA binding & Zinc & 3.65 & $4.02 \mathrm{E}-09$ \\
\hline
\end{tabular}

activities may be affected by phosphorylation. The phosphorylation of ETR1 requires an ethylene-binding domain and copper (Bisson and Groth 2012). Decreases in phosphorylation may be blocked by the presence of silver ions. An $\mathrm{AgNO}_{3}$ treatment of cucumber plants reportedly can influence flower sex determination by inducing the formation of male flowers (Malepszy and Niemirowicz-Szczytt 1991). Thus, we propose that this is correlated with a decrease in the sensitivity of ethylene receptors. Nevertheless, it appears that copper homeostasis is very important for ethylene perception and signaling.

The gene encoding COPT1, which belongs to another copper transporter family, is highly expressed in females. This protein enables copper in the soil to enter plant cells (Sancenón et al. 2003). The uptake of exogenous copper essentially depends on COPT1 in the plasma membrane. The entry of large amounts of $\mathrm{Cu}(\mathrm{I})$ generates a burst of $\mathrm{OH}^{-}$, which activates $\mathrm{Ca}^{2+}$ influx channels and induces the opening of $\mathrm{K}^{2+}$ efflux channels, thereby activating a caspase-like protein-induced PCD (Rodrigo-Moreno et al. 2013). These changes may be responsible for inhibiting organ growth (e.g., root elongation) in A. thaliana (Rodrigo-Moreno et al. 2013). A previous study revealed some PCD occurring in cucumber male flower buds, which may be evidence of stamen inhibition through PCD (Delorme et al. 2000). However, it is still unclear whether such PCD is correlated with copper and how this phenomenon may be related to sex determination in cucumber flowers.

In summary, we identified proteins correlated with copper and its transporters, and determined that the corresponding genes are differentially expressed between sex types. We assume that the expression-level differences result in diverse copper transport in cells. This ultimately leads to differences in the quality and quantity of the copper available to ethylene receptors, which may affect receptor activity. Receptor efficiency is the basis for the signal transmission in the ethylene signaling pathway, or the redistribution of auxin. Finally, changes in copper homeostasis may induce PCD in unwanted floral bud organs, leading to the formation of unisexual flowers. Additionally, diversity in the expression of genes encoding proteins correlated with copper and homeostasis in developing floral buds as well as the co-participation of 
ions in specific processes affecting flower morphogenesis may influence the cucumber sex determination.

Another group of DEGs was related to zinc. Like copper, zinc can influence ethylene production (Mertens et al. 1999). We identified several genes encoding zinc finger proteins specific to males (Cucsa.173610 and Cucsa.259930), females (Cucsa.116850, Cucsa.078040, Cucsa.205210, and Cucsa.175700), and hermaphrodites (Cucsa.322240 and Cucsa.280660). Zinc finger ( $\mathrm{Znf} \mathrm{C} 2 \mathrm{H} 2)$ domains are relatively small protein motifs that contain multiple finger-like protrusions that make tandem contacts with their target molecule. These domains bind zinc or other metals (Gamsjaeger et al. 2007). In a recent study of banana fruit ripening, ethylene was observed to activate $\mathrm{C} 2 \mathrm{H} 2$ proteins, which repressed the expression of ethylene biosynthetic genes (ACSI and ACOI) by directly binding to the promoters (Han et al. 2016). On the basis of a study examining Cucumis melo, the gy sex gene is presumably a member of the WIP family. The WIP gene in melon encodes a transcription factor domain $\mathrm{C} 2 \mathrm{H} 2$ zinc finger protein (Boualem et al. 2015, 2016; Martin et al. 2009; Renner 2016). This gene controls the development of male flowers, as the loss-offunction mutant carrying the recessive form produces only female flowers (Boualem et al. 2008). Little is known about the cucumber WIP gene family and its correlation with sex determination. A recent study investigating ethylene perception and the subsequent signal transmission revealed that cucumber CsWIP1 binds to the $\mathrm{Cs} A C O 2$ promoter to repress expression. The $\mathrm{CSACO} 2$ gene is necessary for the production of female flowers, and the encoded protein functions cooperatively with CsACS11 to provide the necessary ethylene for carpel development (Chen et al. 2016). It appears likely that zinc finger proteins are associated with sex determination in cucumber, although this possibility will need to be experimentally verified.

\section{Cell wall and cytoskeleton}

Proper cell wall assembly is very important, especially during pollen formation and pollen tube growth. The improper accumulation of callose and pectins in the cell wall results in abnormal pollen tube growth (Sede et al. 2018). Pectins are an important component of the pollen tube cell wall. Consequently, pectin-modifying proteins are important for rearranging the cell wall. Thus, pectin clearly affects the structure and chemical composition of pollen tube cell walls (Mollet et al. 2013). Moreover, pectin was observed between microspores, which is very important for the creation of the microspore tetrad. In mutants in which many of the pectin esterase-associated genes were not expressed, the resulting microspore tetrads dissolved (Jakobsen et al. 2005). In this study, we confirmed that genes encoding proteins associated with the production and modification of pectins and cell wall rearrangements are in one related group. Additionally, these genes were more highly expressed in male flowers than in female or hermaphroditic flowers (Fig. 8 bin 10, Tables 6, S3, and S9). Proper pollen development is among other factors, one of the basis of successful fertilization and reproduction. We identified several genes related to pectin metabolism in the male cucumber lines, including pectin invertase or methylesterase (Cucsa.181720, Cucsa.374170, Cucsa.069220, Cucsa.069220, Cucsa.374150, and Cucsa.286280). According to a previous study, manipulating pectin within the cell wall may also affect organ emergence in the shoot apex (Peaucelle et al. 2011). In A. thaliana, the gene encoding a pectin lyase-like (PLL) protein is highly expressed in the stamen because of the regulated stamen abscission during floral bud cell separations (Sun et al. 2010). In this study, we also identified genes encoding PLL proteins (Cucsa.005440, Cucsa.339080, Cucsa.099870, Cucsa.124080, and Cucsa.142040) that are likely involved floral bud cell separation. During periods of intensive growth, like in differentiating buds, dynamic remodeling of the cell wall occurs. We identified genes (10\%) correlated with cell wall modifications as well as the cytoskeleton and membranes. These genes were differentially expressed among the floral bud sex types. In plants, organ emergence requires cell expansion, which is controlled by turgor pressure and cell wall relaxation. As such, organ emergence likely requires changes to the cell wall mechanics. The manipulation of pectins within the cell walls of the meristem affects organ emergence. These cell wall changes are accompanied by cytoskeleton modifications. We detected the profilin gene (Cucsa.116730) as a DEG that was highly expressed in the male cucumber line. The encoded actin-binding protein contributes to the dynamic turnover and restructuring of the cytoskeleton. Additionally, profilin is important for the spatial and temporal control of microfilament growth, which is an essential process for cellular locomotion and changes to cell shapes (Gunning et al. 2015). Among other genes, we identified the gene encoding the TUA4 tubulin (Cucsa.219020) required for transporting cell wall components (Holmes-Davis et al. 2005), the gene encoding formin (Cucsa.103120), which mediates the elongation of filaments (Gunning et al. 2015), and the gene encoding the LIM domain-containing protein (Cucsa.101820) responsible for cytoskeleton organization and protein interactions. During floral bud development, the cell wall, cytoskeleton, tubules, filaments, and plasma membrane are considerably modified. Cell differentiation alters cell plasticity via many morphological and biochemical modifications to the cell membrane networks.

We also identified many membrane-related genes (Tables 6, S3, and S9) with specific expression patterns in different floral bud sex types. The encoded proteins are likely to function in the reconstruction and organization 
Table 6 Differentially expressed genes related to the cell wall and membrane

\begin{tabular}{|c|c|c|c|c|c|}
\hline Comparison & Gene ID & Description & specificity & $\log 2 \mathrm{FC}$ & Adj p-val \\
\hline Female FvM & Cucsa.309270 & Cellulose synthase-like B3 & Cell wall & -2.17 & $8.36 \mathrm{E}-03$ \\
\hline Female FvM & Cucsa. 170430 & Glycine-rich protein & Cell wall & -2.75 & $1.58 \mathrm{E}-22$ \\
\hline Female FvM & Cucsa. 124350 & Plasma membrane intrinsic protein $2 \mathrm{~A}$ & Membrane & -2.33 & $1.09 \mathrm{E}-03$ \\
\hline Female FvM & Cucsa. 345810 & ENTH/ANTH/VHS superfamily protein & Membrane & -2.21 & $1.62 \mathrm{E}-03$ \\
\hline Herma FvH & Cucsa.083360 & Endomembrane protein 70 protein family & Membrane & Inf & $2.20 \mathrm{E}-06$ \\
\hline Herma FvH & Cucsa.381310 & Rhomboid-related intramembrane serine protease & Membrane & 2.86 & $2.16 \mathrm{E}-02$ \\
\hline Herma MvH & Cucsa.101820 & LIM domain-containing protein & Cytoskeleton & 1.57 & $5.64 \mathrm{E}-04$ \\
\hline Male FvM & Cucsa.303610 & Cellulase (glycosyl hydrolase family 5) protein & Cell wall & Inf & $5.54 \mathrm{E}-07$ \\
\hline Male FvM & Cucsa.322580 & Glycosyl hydrolase 9B13 & cell wall & 1.44 & $1.10 \mathrm{E}-04$ \\
\hline Male FvM & Cucsa.146880 & Glycosyl hydrolase family protein & Cell wall & 1.36 & $3.22 \mathrm{E}-02$ \\
\hline Male FvM & Cucsa.292650 & Xyloglucan endotransglucosylase/hydrolase 32 & Cell wall & 2.29 & $2.16 \mathrm{E}-02$ \\
\hline Male FvM & Cucsa.181720 & Plant invertase/pectin methylesterase inhibitor & Cell wall & Inf & $2.17 \mathrm{E}-04$ \\
\hline Male FvM & Cucsa.374170 & Plant invertase/pectin methylesterase inhibitor & Cell wall & 5.85 & $3.17 \mathrm{E}-03$ \\
\hline Male FvM & Cucsa.099870 & Pectin lyase-like superfamily protein & Cell wall & 2.12 & $1.10 \mathrm{E}-03$ \\
\hline Male FvM & Cucsa.124080 & Pectin lyase-like superfamily protein & Cell wall & $\operatorname{Inf}$ & $1.46 \mathrm{E}-02$ \\
\hline Male FvM & Cucsa.142040 & Pectin lyase-like superfamily protein & Cell wall & 2.23 & $6.20 \mathrm{E}-08$ \\
\hline Male FvM & Cucsa.069220 & Plant invertase/pectin methylesterase inhibitor & Cell wall & 7.10 & $3.82 \mathrm{E}-03$ \\
\hline Male FvM & Cucsa.374150 & Plant invertase/pectin methylesterase inhibitor & Cell wall & 8.76 & $7.71 \mathrm{E}-04$ \\
\hline Male FvM & Cucsa.286280 & Plant invertase/pectin methylesterase inhibitor & Cell wall & 7.14 & $5.89 \mathrm{E}-05$ \\
\hline Male FvM & Сucsa.005440 & Pectate lyase family protein & Cell wall & Inf & $8.32 \mathrm{E}-04$ \\
\hline Male FvM & Сисsa.339080 & Pectate lyase family protein & Cell wall & 10.24 & $2.24 \mathrm{E}-06$ \\
\hline Male FvM & Cucsa.103120 & formin homolog 6 & Cytoskeleton & 1.25 & $1.21 \mathrm{E}-02$ \\
\hline Male FvM & Cucsa.231850 & thioredoxin H-type 1 & Membrane & 2.52 & $1.61 \mathrm{E}-05$ \\
\hline Male FvM & Cucsa.161790 & $\mathrm{H}(+)$-ATPase 5 & Membrane & 2.17 & $1.51 \mathrm{E}-09$ \\
\hline Male FvM & Cucsa.134700 & Leucine-rich repeat transmembrane protein kinase & Membrane & 2.88 & $1.15 \mathrm{E}-04$ \\
\hline Male FvM & Cucsa.116730 & profilin 4 & Membrane & 3.52 & $1.19 \mathrm{E}-05$ \\
\hline Male FvM & Cucsa.140680 & Leucine-rich repeat transmembrane protein kinase & Membrane & 1.05 & $1.54 \mathrm{E}-02$ \\
\hline Male FvM & Cucsa.339600 & Nodulin MtN3 family protein & Membrane & Inf & $6.81 \mathrm{E}-09$ \\
\hline Male FvM & Cucsa.142760 & Early nodulin-like protein 20 & Membrane & Inf & $2.24 \mathrm{E}-06$ \\
\hline Male FvM & Cucsa.157120 & Nodulin MtN3 family protein & Membrane & 4.53 & $4.88 \mathrm{E}-09$ \\
\hline Male FvM & Сисsa.303950 & Nodulin MtN3 family protein & Membrane & 1.18 & $2.97 \mathrm{E}-02$ \\
\hline
\end{tabular}

of developing sex organs. Several genes were identified as nodulin genes (Cucsa.142760, Cucsa.339600, Cucsa.157120, and Cucsa.303950), which are highly expressed in male flowers because of their specific role related to pollen formation. An earlier A. thaliana study indicated the nodulin protein with MtN3 domains is a plasma membrane protein specific to male flowers because it is required for the exine pattern of microspores (Guan et al. 2008).

Ethylene and auxins influence cell wall elongation, growth, and inhibition. Ethylene and auxin gradients between cells may affect several cellular activities, including cell extension, cell differentiation (Bashline et al. 2014; Osborne 1979), and remobilization of cell wall pectins (Zhu et al. 2016). It is likely that the changes occurring in the cell wall during the differentiation of shoot apical cells are part of the processes mediating sex determination in cucumber flowers because of their effects on the differentiation of generative organs.

\section{Transporters and cytochromes}

Signals received by cells affect cell activities. Many enzymes are involved in the transmission of signals, as are some transporters. The ABC transporter family is very large, with members mediating transmembrane transport and/or regulating other transporters (Rea 2007). The ABC proteins involve ATP during the transport of diverse substrates (e.g., lipids, heavy metal ions, sugars, amino acids, peptides, and secondary metabolites) (Jasinski et al. 2003) as well as auxin (Rea 2007) across various membranes. The ABC transporters encoded by the genes identified in this study (Cucsa.139230, Cucsa.158700, Cucsa.074620, and Cucsa.012820) react with many proteins that vary regarding molecular function 
(Fig. 8 bin $4 \mathrm{a}$ and b, Table S9). Interestingly, the expression patterns for these genes differed among the male, female, and hermaphroditic plants, suggesting the encoded proteins serve as transporters for different processes related to the determination of flower sex type. Specifically, ABCG31 is specific to male flowers, and is included in the central node of bin $4 \mathrm{~b}$. This protein was observed to interact with 23 proteins in main molecular network (Fig. 8), implying that it is a multitasking protein. Choi et al. proved that ABCG31 influences pollen coat maturation, possibly by regulating the distribution of steryl glycosides, thereby altering the membrane properties at the pollen surface, which affects pollen fitness (Choi et al. 2014). We identified several other transport-related genes (3.87\%) (Tables 7, S3, and S9) which are involved in many processes in the differentiating cell, but their direct impact on sex expression is not clear.

The ABCG31 transporter also interacts with cytochromes (Fig. 8 bins $4 \mathrm{~b}$ and 3). The DEGs included several genes encoding cytochromes $(2.9 \%)$, such as BCS1 (Cucsa.043090), BAS1 (Cucsa.293490), CYP75B1 (Cucsa.149540), CYP71B2 (Cucsa.286690), CYP71B37 (Cucsa.286680), CYP716A1 (Cucsa.356140), CYP72A15 (Cucsa.058110), and CYP88A3 (Cucsa.257180). These genes were highly expressed in the female shoot apex. In contrast, only one cytochrome gene, CYP78A10 (Cucsa.113360), was highly expressed in the male shoot apex (Tables S3 and S9). Cytochromes are involved in flower morphogenesis and reproduction (Larkin 1994; Petkova-Andonova et al. 2002). Cytochrome P450 regulates many important cell processes affecting plant growth and development. Some P450 genes are expressed during cell wall synthesis, and the encoded proteins are important for regulating plant hormone metabolism (Jun et al. 2015). Cytochrome P450 is involved in the biosynthesis of auxins, cytokinins, jasmonic acid, gibberellins, and ABA (Jun et al. 2015), and also affects ethylene metabolism (Chang et al.
2014). According to Chang et al. (2014), repression by the ethylene receptor ETR1 depends on an integral membrane protein, REVERSION-TO-ETHYLENE SENSITIVITY 1 (RTE1), Cytochrome b5 might activate RTE1 through a redox modification, thus serving as the link between cellular redox status and ethylene signaling via the ETR1 ethylene receptor isoform. Alternatively, ETR1 conformation may be highly sensitive to changes in membrane composition and fluidity that are affected by the cytochrome-controlled unsaturated fatty acid content of membrane lipids (Chang et al. 2014). Cytochrome $\mathrm{P} 450$ helps form the exine layer of the outer pollen wall to produce normal mature pollen grains (Pinot and Beisson 2011). The cytochromes are commonly involved in the synthesis of secondary metabolites and the regulation of plant hormone metabolism. However, the role of the cytochromes encoded by DEGs identified in this study remains unclear.

\section{Lipid and sugar metabolism}

Plants require lipids for membrane biogenesis, as signal molecules, and as a form of stored carbon and energy (Schmid 2015). Lipids are present in membranes and influence cytoskeleton plasticity. Ethylene can influence lipids in the membranes (Jia and Li 2015). We identified DEGs (5.8\%) related to lipid metabolism (Tables $8, \mathrm{~S} 3$, and S9). We speculate that in developing floral buds, the newly created male and female organs may be differentially sensitive to ethylene because of differences in lipid metabolism. Moreover, the synthesis of lipid components in anthers is essential for male reproductive development in plants, although the functions of these components have not been characterized. The lipid-based anther cuticle together with the pollen exine represents the two main protective barriers for microspores and pollen grains against various abiotic and biotic stresses (Zhang et al. 2010).

Table 7 Differentially expressed genes related to transport

\begin{tabular}{|c|c|c|c|c|c|}
\hline Comparison & Gene ID & Description & Specificity & $\log 2 \mathrm{FC}$ & Adj $p$ value \\
\hline Female FvM & Сисsa.158700 & $\mathrm{ABC}$ transporter family protein & Transport & -1.06 & $1.40 \mathrm{E}-02$ \\
\hline Female FvM & Cucsa.309410 & Major facilitator superfamily protein & Transport & -0.98 & $1.45 \mathrm{E}-02$ \\
\hline Female FvM & Cucsa.339350 & Major facilitator superfamily protein & Transport & -1.62 & $3.14 \mathrm{E}-03$ \\
\hline Female FvM & Сисsа.338920 & NOD26-like intrinsic protein $1 ; 2$ & Transport & -1.84 & $4.43 \mathrm{E}-05$ \\
\hline Female FvM & Cucsa.193190 & NOD26-like intrinsic protein $5 ; 1$ & Transport & -1.68 & $2.43 \mathrm{E}-05$ \\
\hline Female FvM & Сисsa.217790 & Sulfate transporter $1 ; 1$ & Transport & -1.46 & $1.47 \mathrm{E}-03$ \\
\hline Herma MvH & Cucsa.012820 & Multidrug resistance-associated protein 14 & Transport & 1.25 & $2.25 \mathrm{E}-02$ \\
\hline Male FvM & Сисsa.139230 & Pleiotropic drug resistance 3 & Transport & 2.91 & $3.31 \mathrm{E}-03$ \\
\hline Male FvM & Cucsa.074620 & $\mathrm{ABC}-2$ type transporter family protein & Transport & 8.28 & $2.90 \mathrm{E}-12$ \\
\hline Male FvM & Сисsa.142980 & Major facilitator superfamily protein & Transport & Inf & $2.65 \mathrm{E}-02$ \\
\hline Male FvM & Cucsa.254190 & Major facilitator superfamily protein & Transport & 1.84 & $1.63 \mathrm{E}-02$ \\
\hline Male FvM & Сucsa.160900 & MATE efflux family protein & Transport & 1.53 & $8.18 \mathrm{E}-03$ \\
\hline
\end{tabular}


Table 8 Differentially expressed genes related to lipid metabolism

\begin{tabular}{|c|c|c|c|c|c|}
\hline Comparison & Gene ID & Description & Specificity & $\log 2 \mathrm{FC}$ & Adj $p$ value \\
\hline Female FvM & Cucsa.019600 & Bifunctional inhibitor/lipid-transfer protein & Lipid & -1.63 & $2.16 \mathrm{E}-06$ \\
\hline Female FvM & Сисsa.320750 & Bifunctional inhibitor/lipid-transfer protein & Lipid & -1.37 & $4.89 \mathrm{E}-05$ \\
\hline Female FvM & Cucsa.320770 & Bifunctional inhibitor/lipid-transfer protein & Lipid & -2.73 & $1.73 \mathrm{E}-12$ \\
\hline Female FvM & Cucsa.096300 & Fatty acid desaturase 5 & Lipid & -2.72 & $6.75 \mathrm{E}-05$ \\
\hline Female FvM & Cucsa.250860 & PEBP (phosphatidylethanolamine-binding protein) & Lipid & -2.92 & $5.81 \mathrm{E}-04$ \\
\hline Female FvM & Cucsa.091270 & lipoxygenase 1 & Lipid & -1.76 & $2.56 \mathrm{E}-07$ \\
\hline Female FvM & Cucsa.091280 & PLAT/LH2 domain-containing lipoxygenase & Lipid & -1.72 & $2.56 \mathrm{E}-07$ \\
\hline Herma MvH & Сисsa.091380 & Lipoxygenase 1 & Lipid & 1.65 & $2.79 \mathrm{E}-03$ \\
\hline Male FvM & Сисsа.096340 & Fatty acid desaturase 5 & Lipid & 7.99 & $3.22 \mathrm{E}-16$ \\
\hline Male FvM & Сисsa.340370 & 3-Ketoacyl-CoA synthase 7 & Lipid & 5.32 & $1.37 \mathrm{E}-14$ \\
\hline Male FvM & Cucsa.199000 & Bifunctional inhibitor/lipid-transfer protein & Lipid & 4.66 & $7.62 \mathrm{E}-12$ \\
\hline Male FvM & Cucsa.257050 & Fatty acid hydroxylase superfamily & Lipid & 1.11 & $5.89 \mathrm{E}-03$ \\
\hline Male FvM & Сисsa.257060 & Fatty acid hydroxylase superfamily & Lipid & 2.70 & $2.40 \mathrm{E}-05$ \\
\hline Male FvM & Сисsa.304270 & GDSL-like Lipase/Acylhydrolase superfamily protein & Lipid & 6.34 & $7.50 \mathrm{E}-03$ \\
\hline Male FvM & Сисsa.360940 & GDSL-like Lipase/Acylhydrolase superfamily protein & Lipid & 2.39 & $9.14 \mathrm{E}-05$ \\
\hline Male FvM & Cucsa.054230 & Myzus persicae-induced lipase 1 & Lipid & 1.94 & 4.07E-02 \\
\hline Male FvM & Cucsa.161220 & Polyketide cyclase/dehydrase and lipid transport & Lipid & 2.78 & $1.51 \mathrm{E}-06$ \\
\hline Male FvM & Сисsa.372130 & Polyketide cyclase/dehydrase and lipid transport & Lipid & 2.36 & $2.24 \mathrm{E}-06$ \\
\hline
\end{tabular}

Table 9 Differentially expressed genes related to sugar metabolism

\begin{tabular}{|c|c|c|c|c|c|}
\hline Comparison & Gene ID & Description & Specificity & $\log 2 \mathrm{FC}$ & Adj p-val \\
\hline Female FvM & Cucsa.334200 & Aldolase superfamily protein & Sugar & -1.01 & $1.67 \mathrm{E}-02$ \\
\hline Female FvM & Cucsa.046350 & dormancy-associated protein-like 1 & Sugar & -0.93 & $1.54 \mathrm{E}-02$ \\
\hline Female FvM & Cucsa.089500 & Glucose-methanol-choline (GMC) oxidoreductase & Sugar & -1.69 & $3.46 \mathrm{E}-02$ \\
\hline Female FvM & Cucsa.321550 & Haloacid dehalogenase-like hydrolase (HAD) & Sugar & -1.81 & $1.51 \mathrm{E}-09$ \\
\hline Female FvM & Cucsa.109770 & polyol/monosaccharide transporter 5 & Sugar & -1.00 & $1.79 \mathrm{E}-02$ \\
\hline Female FvM & Cucsa.334200 & Aldolase superfamily protein & Sugar & -1.01 & $1.67 \mathrm{E}-02$ \\
\hline Herma FvH & Cucsa.081220 & Galactose mutarotase-like superfamily protein & Sugar & Inf & $7.63 \mathrm{E}-17$ \\
\hline Herma FvH & Cucsa.359700 & Glucose-methanol-choline (GMC) oxidoreductase & Sugar & 3.09 & $1.72 \mathrm{E}-05$ \\
\hline Herma MvH & Cucsa. 166390 & Phloem protein 2-A13 & Sugar & 1.40 & $2.85 \mathrm{E}-02$ \\
\hline Male FvM & Cucsa. 256730 & Nucleotide-diphospho-sugar transferase & Sugar & 5.83 & $1.89 \mathrm{E}-02$ \\
\hline Male FvM & Cucsa. 254230 & Beta-galactosidase 7 & Sugar & Inf & $5.22 \mathrm{E}-04$ \\
\hline Male FvM & Cucsa.336940 & Beta glucosidase 11 & Sugar & 5.13 & $1.17 \mathrm{E}-19$ \\
\hline Male FvM & Cucsa.042020 & Beta-amylase 4 & Sugar & 2.12 & $7.71 \mathrm{E}-04$ \\
\hline Male FvM & Cucsa. 109300 & Beta-galactosidase 3 & Sugar & 4.37 & $4.37 \mathrm{E}-06$ \\
\hline Male FvM & Cucsa. 284640 & Glucuronidase 2 & Sugar & 4.20 & $8.48 \mathrm{E}-03$ \\
\hline Male FvM & Cucsa.154490 & Haloacid dehalogenase-like hydrolase (HAD) & Sugar & 1.75 & $9.14 \mathrm{E}-05$ \\
\hline Male FvM & Cucsa.167470 & Lectin-related & Sugar & 2.21 & $1.51 \mathrm{E}-02$ \\
\hline Male FvM & Cucsa.104560 & Myo-inositol-1-phosphate synthase 2 & Sugar & 0.98 & $2.40 \mathrm{E}-02$ \\
\hline Male FvM & Cucsa. 332640 & Phosphofructokinase family protein & Sugar & 2.37 & $1.46 \mathrm{E}-08$ \\
\hline Male FvM & Сисsa.349380 & Senescence-associated gene 29 & Sugar & 8.35 & $4.89 \mathrm{E}-02$ \\
\hline Male FvM & Cисsa. 088480 & Sucrose-phosphate synthase family protein & Sugar & 1.68 & $4.68 \mathrm{E}-04$ \\
\hline Male FvM & Cucsa.302770 & Sugar transporter 1 & Sugar & Inf & $2.30 \mathrm{E}-03$ \\
\hline Male MvH & Cucsa.340510 & Aldolase-type TIM barrel family protein & Sugar & -1.88 & $2.76 \mathrm{E}-02$ \\
\hline
\end{tabular}


Almost $7 \%$ of the identified DEGs were related to sugar metabolism (Tables 9, S3, and S9). Previous studies proved the involvement of the sugar signaling pathway during cucumber flower sex determination (Terefe and Tatlioglu 2005; Miao et al. 2010). The contents of sugars (e.g., sucrose and glucose) in the shoot apex are correlated with plant femaleness under different temperature conditions. The relevant functions of sugar signaling are unclear. The results of an earlier study (Miao et al. 2010) indicated that femaleness is enhanced by the accumulation of sugar in the shoot apices under low temperature. Additionally, sugars might influence ethylene signaling by controlling Ethylene Response 1 expression (Sulmon et al. 2007). The accumulation of sugar induced by low temperatures upregulates ACS2 expression, leading to ethylene biosynthesis and femaleness (Miao et al. 2010).

\section{Ubiquitination processes}

We identified an interesting group of genes that were related to the ubiquitin proteasome system (UPS), which degrades proteins. Some of the UPS-related genes (Tables S3 and S9) exhibited upregulated expression in females [RING proteins (Cucsa.046340 and Cucsa.132720) and polyubiquitin protein (Cucsa.266970)] and in males [F-box proteins (Cucsa.198720 and Cucsa.351010), BTB protein (broad-complex/tramtrack/bric-a-brac protein that recruits substrates to be degraded) (Cucsa.103110), and ubiquitinlike protein (Cucsa.148380)]. Ubiquitination involves the following three major enzymes: E1 activating enzyme, E2 conjugating enzyme, and E3 ubiquitin ligase. One of the best characterized RING ligases, the SCF (Skp-Cullin-F-box) complex, is composed of four major components, namely Skp1, Cul1/Cdc53, Roc1/Rbx1/Hrt1, and F-box protein (Ho et al. 2006). We identified a DEG encoding an F-box protein. The SCF/F-box-mediated ubiquitination processes provide control over the stability of proteins and play essential roles in many aspects of development. Both the E2 and E3 enzymes coordinate the transfer of ubiquitin onto a selected target and ultimately create a chain of ubiquitin molecules on the target. Ubiquitination can influence protein functions by directing cellular localization, modulating activation, and controlling abundance. Moreover, the UPS is crucial for the regulation of ethylene biosynthesis because it influences ACS synthase abundance and activity (Lyzenga and Stone 2012). This process may be affected by light intensity (Yoon and Kieber 2013). Interestingly, light also influences sex determination in cucumber flowers. We identified femalespecific, light chain-related genes that exhibited upregulated expression in female cucumber lines (Cucsa.067140 and Cucsa.341570). These genes may affect the development of floral bud sex types. There may also be an additional rate-limiting factor that mediates ethylene biosynthesis, with implications for phenotype development. Ubiquitination is also involved in PCD. There is currently no evidence that PCD occurs in cucumber floral buds, although some PCDrelated phenomena have been observed in differentiating floral buds (Hao et al. 2003).

The data presented herein confirms that flower development involves the differential expression of vast number of genes. As many of DEGs determined in this study are known or predicted to have regulatory functions, it appears that the gene networks controlling floral organogenesis are very complex. Additional studies of selected genes are needed.

However, because they have minor and complex roles in flower formation, detailed functional characterizations via gene inactivation using modern techniques (e.g., genome editing with CRISPR/Cas9 or transformation) may be difficult because of a lack of a readily discernable sex mutant. The growing need to elucidate the functions of specific proteins and related interaction pathways in molecular networks is the driving force behind the development of analytical techniques (e.g., genome editing). It will soon be possible to efficiently generate full loss-of-function alleles and subsequently create lines with multiple genes knocked out. Thus, many additional regulators of flower development will likely be discovered in the near future, and this will lead to an increasingly comprehensive view of the gene sets that control floral organogenesis (Thomson et al. 2017). Even though transcripts correlated with sex expression in cucumber have been extensively studied (Guo et al. 2010; Przybecki et al. 2003, 2004; Wu et al. 2010) till now there is no clear view what is happening in developing floral buds.

Herein, we confirm that cucumber sex determination is a very complex process involving more metabolic pathways than previously thought (e.g., ethylene biosynthesis and other hormone-signaling pathways). Confirming the involvement of potential regulatory processes, such as ion homeostasis, cell wall and cytoskeleton modifications, ubiquitination, lipid and sugar metabolism, and gene expression mediated by transcription factors, represents an interesting challenge for researchers interested in gaining further insights into the cucumber sex determination process.

\section{Conclusions}

High-quality transcriptome datasets for cucumber leaves and the shoot apex (with developing flower buds) were obtained using the Illumina HiSeq 2000 sequencing platform. A significant number of important metabolic pathways and functions associated with the unigenes were identified. Many candidate genes that are potentially involved in flower morphogenesis were applied to create a molecular network of interactions involving transcription factors, hormones, metal ions, cell wall and cytoskeleton modifications, transporters, 
cytochromes, sugars, lipids, and ubiquitination pathways. This molecular network may be useful for future studies regarding cucumber flower sex determination. Future studies involving more individuals from different genetic backgrounds grown under different environmental conditions are needed to assess the utility of specific transcripts as tissue- and/or sex-specific markers. Future investigations on the regulation of our candidate genes may enable researchers and breeders to control or select specific sexual expression patterns in cucumber. The functional annotation of high-throughput transcriptomic data generated in this study may serve as genetic resources for the development of crop improvement strategies for cucumber and other related crops.

Author contribution statement MP, ZP, and RKW designed and conceived the experiments. MP, AS, and LP completed the experiments. MP, LP, AS, JR, and KP analyzed the data. MP and WP wrote the manuscript.

Acknowledgements We would like to thank Prof. Stefan Malepszy (Warsaw University of Life Sciences, Poland) for valuable comments concerning this research. This research was supported by the National Science Center (Project No. NCN 2011/01/B/NZ2/01631). We also would like to thank Michał Wojcieszek for help in data deposition. We thank Edanz Group (www.edanzediting.com/ac) for editing a draft of this manuscript.

\section{Compliance with ethical standards}

Conflict of interest The authors declare that they have no conflict of interest.

Availability of supporting data All clean reads generated by Illumina sequencing have been deposited in the Sequence Read Archive database (http://www.ncbi.nlm.nih.gov/sra) under BioProject PRJNA359788 (female flowers: SAMN06198244 and SAMN06198177; male flowers: SAMN06198176, SAMN06198229, SAMN06198230, and SAMN06198221; hermaphroditic flowers: SAMN06198219 and SAMN06198226; leaves: SAMN06198227 and SAMN06198228).

Open Access This article is distributed under the terms of the Creative Commons Attribution 4.0 International License (http://creativeco mmons.org/licenses/by/4.0/), which permits unrestricted use, distribution, and reproduction in any medium, provided you give appropriate credit to the original author(s) and the source, provide a link to the Creative Commons license, and indicate if changes were made.

\section{References}

Alonso JM, Hirayama T, Roman G, Nourizadeh S, Ecker JR (1999) EIN2, a bifunctional transducer of ethylene and stress responses in Arabidopsis. Science 284:2148-2152
Ambawat S, Sharma P, Yadav NR, Yadav RC (2013) MYB transcription factor genes as regulators for plant responses: an overview. Physiol Mol Biol Plants 19:307-321

Anders S, Huber W (2010) Differential expression analysis for sequence count data. Genome Biol 11:R106

Bai SL, Peng YB, Cui JX, Gu HT, Xu LY, Li YQ et al (2004) Developmental analyses reveal early arrests of the spore-bearing parts of reproductive organs in unisexual flowers of cucumber (Cucumis sativus L.). Planta 220:230-240

Bao Y, Wang C, Jiang C, Pan J, Zhang G, Liu H, Zhang H (2014) The tumor necrosis factor receptor-associated factor (TRAF)like family protein SEVEN IN ABSENTIA 2 (SINA2) promotes drought tolerance in an ABA-dependent manner in Arabidopsis. New Phytol 202:174-187

Bashline L, Lei L, Li S, Gu Y (2014) Cell wall, cytoskeleton, and cell expansion in higher plants. Mol Plant 7:586-600

Bell EM, Lin WC, Husbands AY, Yu L, Jaganatha V, Jablonska B et al (2012) Arabidopsis lateral organ boundaries negatively regulates brassinosteroid accumulation to limit growth in organ boundaries. Proc Natl Acad Sci USA 109:21146-21151

Bisson MMA, Groth G (2012) Cyanide is an adequate agonist of the plant hormone ethylene for studying signalling of sensor kinase ETR1 at the molecular level. Biochem J 444:261-267

Boualem A, Fergany M, Fernandez R, Troadec C, Martin A, Morin H et al (2008) A conserved mutation in an ethylene biosynthesis enzyme leads to andromonoecy in melons. Science 321:836-838

Boualem A, Troadec C, Camps C, Lemhemdi A, Morin H, Sari MA et al (2015) A cucurbit androecy gene reveals how unisexual flowers develop and dioecy emerges. Science 350:688-691

Boualem A, Lemhemdi A, Sari MA, Pignoly S, Troadec C, Choucha FA et al (2016) The andromonoecious sex determination gene predates the separation of cucumis and citrullus genera. PLoS ONE 11:e0155444

Bowman JL, Smyth DR, Meyerowitz EM (2012) The ABC model of flower development: then and now. Development 139:4095-4098

Chandler JW (2011) The hormonal regulation of flower development. J Plant Growth Regul 30:242-254

Chang J, Clay JM, Chang C (2014) Association of cytochrome b5 with ETR1 ethylene receptor signaling through RTE1 in Arabidopsis. Plant J 77:558-567

Chen H, Sun J, Li S, Cui Q, Zhang H, Xin F et al (2016) An ACC oxidase gene essential for cucumber carpel development. Mol Plant 9:1315-1327

Choi H, Ohyama K, Kim YY, Jin JY, Lee SB, Yamaoka Y, Lee Y (2014) The role of Arabidopsis ABCG9 and ABCG31 ATP binding cassette transporters in pollen fitness and the deposition of steryl glycosides on the pollen coat. Plant Cell 113:118935

Coen ES, Meyerowitz EM (1991) The war of the whorls: genetic interactions controlling flower development. Nature 353:31-37

Conesa A, Götz S (2008) Blast2GO: A comprehensive suite for functional analysis in plant genomics Int J Plant Genomics

Delorme VG, McCabe PF, Kim DJ, Leaver CJ (2000) A matrix metalloproteinase gene is expressed at the boundary of senescence and programmed cell death in cucumber. Plant Physiol 123:917-927

Finn RD, Mistry J, Tate J, Coggill P, Heger A, Pollington JE et al (2009) The Pfam protein families database. Nucleic Acids Res 38:D211-D222

Gamsjaeger R, Liew CK, Loughlin FE, Crossley M, Mackay JP (2007) Sticky fingers: zinc-fingers as protein-recognition motifs. TIBS 32:63-70

Goodstein DM, Shu S, Howson R, Neupane R, Hayes RD, Fazo J et al (2012) Phytozome: a comparative platform for green plant genomics. Nucleic Acids Res 40:D1178-D1186

Guan YF, Huang XY, Zhu J, Gao JF, Zhang HX, Yang ZN (2008) RUPTURED POLLEN GRAIN1, a member of the MtN3/saliva gene 
family, is crucial for exine pattern formation and cell integrity of microspores in Arabidopsis. Plant Physiol 147:852-863

Gunning PW, Ghoshdastider U, Whitaker S, Popp D, Robinson RC (2015) The evolution of compositionally and functionally distinct actin filaments. J Cell Sci 128:2009-2019

Guo S, Zheng Y, Joung JG, Liu S, Zhang Z, Crasta OR et al (2010) Transcriptome sequencing and comparative analysis of cucumber flowers with different sex type. BMC Genom 11:384

Guo S, Sun B, Looi LS, Xu Y, Gan ES, Huang J, Ito T (2015) Coordination of flower development through epigenetic regulation in two model species: rice and Arabidopsis. Plant Cell Physiol 56:830-842

Hacham Y, Matityahu I, Amir R (2013) Light and sucrose upregulate the expression level of Arabidopsis cystathionine $\gamma$-synthase, the key enzyme of methionine biosynthesis pathway. Amino Acids 45:1179-1190

Han YC, Fu CC, Kuang JF, Chen JY, Lu WJ (2016) Two banana fruit ripening-related $\mathrm{C} 2 \mathrm{H} 2$ zinc finger proteins are transcriptional repressors of ethylene biosynthetic gene. Postharvest Biol Technol 116:8-15

Hao YJ, Wang DH, Peng YB, Bai SL, Xu LY, Li YQ et al (2003) DNA damage in the early primordial anther is closely correlated with stamen arrest in the female flower of cucumber (Cucumis sativus L). Planta 217:888-895

Hay A, Kaur H, Phillips A, Hedden P, Hake S, Tsiantis M (2002) The gibberellin pathway mediates KNOTTED1-type homeobox function in plants with different body plans. Curr Biol 12:1557-1565

Hirayama T, Alonso JM (2000) Ethylene captures a metal! Metal ions are involved in ethylene perception and signal transduction. Plant Cell Physiol 41:548-555

Ho MS, Tsai PI, Chien CT (2006) F-box proteins: the key to protein degradation. J Biomed Sci 13:181-191

Holmes-Davis R, Tanaka CK, Vensel WH, Hurkman WJ, McCormick S (2005) Proteome mapping of mature pollen of Arabidopsis thaliana. Proteomics 5:4864-4884

Hubert O, Piral G, Galas C, Baurens FC, Mbéguié-A-Mbéguié D (2014) Changes in ethylene signaling and MADS box gene expression are associated with banana finger drop. Plant Sci 223:99-108

Jakobsen MK, Poulsen LR, Schulz A, Fleurat-Lessard P, Møller A, Husted $S$ et al (2005) Pollen development and fertilization in Arabidopsis is dependent on the MALE GAMETOGENESIS IMPAIRED ANTHERS gene encoding a type V P-type ATPase. Genes Dev 19:2757-2769

Jasinski M, Ducos E, Martinoia E, Boutry M (2003) The ATP-binding cassette transporters: structure, function, and gene family comparison between rice and Arabidopsis. Plant Physiol $131: 1169-1177$

Jia Y, Li W (2015) Characterisation of lipid changes in ethylene-promoted senescence and its retardation by suppression of phospholipase D $\delta$ in Arabidopsis leaves. Front Plant Sci 6:1045

Jones P, Binns D, Chang HY, Fraser M, Li W, McAnulla C et al (2014) InterProScan 5: genome-scale protein function classification. Bioinformatics 30:1236-1240

Jun XU, Wang XY, Guo WZ (2015) The cytochrome P450 superfamily: key players in plant development and defense. J Integr Agric 14:1673-1686

Kanehisa M, Goto S (2000) KEGG: Kyoto encyclopedia of genes and genomes. Nucleic Acids Res 28:27-30

Kerstetter RA, Laudencia-Chingcuanco D, Smith LG, Hake S (1997) Loss of function mutations in the maize homeobox gene, knotted1, are defective in shoot meristem maintenance. Development 124:3045-3054
Kim C, Jeong DH, An G (2000) Molecular cloning and characterization of OsLRK1 encoding a putative receptor-like protein kinase from Oryza sativa. Plant Sci 152:17-26

Kim D, Pertea G, Trapnell C, Pimentel H, Kelley R, Salzberg SL (2013) TopHat2: accurate alignment of transcriptomes in the presence of insertions, deletions and gene fusions. Genome Biol 14:R36

Lamesch P, Berardini TZ, Li D, Swarbreck D, Wilks C, Sasidharan $R$ et al (2011) The Arabidopsis information resource (TAIR): improved gene annotation and new tools. Nucleic Acids Res 40:D1202-D1210

Larkin J (1994) Isolation of a cytochrome P450 homologue preferentially expressed in developing inflorescences of Zea mays. Plant Mol Biol 25:343-353

Li Z, Huang S, Liu S, Pan J, Zhang Z, Tao Q et al (2009) Molecular isolation of the $\mathrm{M}$ gene suggests that a conserved-residue conversion induces the formation of bisexual flowers in cucumber plants. Genetics 182:1381-1385

Li Z, Wang S, Tao Q, Pan J, Si L, Gong Z, Cai R (2012) A putative positive feedback regulation mechanism in CsACS2 expression suggests a modified model for sex determination in cucumber (Cucumis sativus L). J Exp Bot 63:4475-4484

Liu X, Kim YJ, Müller R, Yumul RE, Liu C, Pan Y et al (2011) AGAMOUS terminates floral stem cell maintenance in Arabidopsis by directly repressing WUSCHEL through recruitment of Polycomb group proteins. Plant Cell 23:3654-3670

Liu H, Zhang B, Wu T, Ding Y, Ding X, Chu Z (2015) Copper ion elicits defense response in Arabidopsis thaliana by activating salicylate-and ethylene-dependent signaling pathways. Mol Plant 8:1550-1553

Loraine A, McCormick S, Estrada A, Patel K, Qin P (2013) Highthroughput sequencing of Arabidopsis thaliana pollen cDNA uncovers novel transcription and alternative splicing. Plant Physiol 112:211441

Lyzenga WJ, Stone SL (2012) Regulation of ethylene biosynthesis through protein degradation. Plant Signal Behav 7:1438-1442

Malepszy S, Niemirowicz-Szczytt K (1991) Sex determination in cucumber (Cucumis sativus) as a model system for molecular biology. Plant Sci 80:39-47

Mao D, Yu F, Li J, Van de Poel B, Tan D, Li J et al (2015) FERONIA receptor kinase interacts with $\mathrm{S}$-adenosylmethionine synthetase and suppresses S-adenosylmethionine production and ethylene biosynthesis in Arabidopsis. Plant Cell Environ 38:2566-2574

Martin A, Troadec C, Boualem A, Rajab M, Fernandez R, Moris H et al (2009) A transposon-induced epigenetic change leads to sex determination in melon. Nature 461:1135-1138

Mertens J, Vangronsveld J, Van Der Straeten D, Van Poucke M (1999) Effects of copper and zinc on the ethylene production of Arabidopsis thaliana. In: Kanellis AK, Chang C, Klee H, Bleecker AB, Pech JC, Grierson D (eds) Biology and biotechnology of the plant hormone ethylene II. Springer, Santorini, pp 333-338

Mi H, Muruganujan A, Casagrande JT, Thomas PD (2013) Large-scale gene function analysis with the PANTHER classification system. Nat Protoc 8:1551

Miao M, Yang X, Han X, Wang K (2010) Sugar signalling is involved in the sex expression response of monoecious cucumber to low temperature. J Exp Bot 62:797-804

Mibus H, Tatlioglu ĆT (2004) Molecular characterization and isolation of the F/f gene for femaleness in cucumber (Cucumis sativus L.). Theor Appl Genet 109:1669-1676

Mistry J, Finn RD, Eddy SR, Bateman A, Punta M (2013) Challenges in homology search: hMMER3 and convergent evolution of coiled-coil regions. Nucleic Acids Res 41:e121-e121 
Mollet JC, Leroux C, Dardelle F, Lehner A (2013) Cell wall composition, biosynthesis and remodeling during pollen tube growth. Plants 2:107-147

Montgomery SB, Sammeth M, Gutierrez-Arcelus M, Lach RP, Ingle C, Nisbett J et al (2010) Transcriptome genetics using second generation sequencing in a Caucasian population. Nature 464:773

Nersissian AM, Valentine JS, Immoos C, Hill MG, Hart PJ, Williams G, Herrmann RG (1998) Uclacyanins, stellacyanins, and plantacyanins are distinct subfamilies of phytocyanins: plant-specific mononuclear blue copper proteins. Prot Sci 7:1915-1929

Osborne D (1979) Control of cell shape and cell size by dual regulation of auxin and ethylene. In: Sunderland N (ed) Perspectives in experimental biology. Elsevier, Oxford, pp 89-102

Pape SL (2012) EasyqpcR: EasyqpcR for easy analysis of real-time PCR data, IRTOMIT-INSERM U1082 IRTOMIT- INSERM:U1082

Pawełkowicz M, Osipowski P, Wojcieszek M, Wóycicki RK, Witkowicz J, Hincha D, Przybecki Z (2012) Identification and characterization of genes connected with flower morphogenesis in cucumber. BioTechnologia 93:123-134

Pawełkowicz M, Zieliński K, Zielińska D, Pląder W, Yagi K, Wojcieszek $M$ et al (2016a) Next generation sequencing and omics in cucumber (Cucumis sativus L.) breeding directed research. Plant Sci 242:77-88

Pawełkowicz M, Wojcieszek M, Osipowski P, Krzywkowski T, Pląder W, Przybecki Z (2016b) Identification and bioinformatics comparison of two novel phosphatases in monoecious and gynoecious cucumber lines. Proc SPIE 10031:100312S

Peaucelle A, Braybrook SA, Le Guillou L, Bron E, Kuhlemeier C, Höfte H (2011) Pectin-induced changes in cell wall mechanics underlie organ initiation in Arabidopsis. Curr Biol 21:1720-1726

Perl-Treves R (1999) Male to female conversion along the cucumber shoot: approaches to studying sex genes and floral development in Cucumis sativus. In: Ainsworth CC (ed) Sex determination in plants. BIOS Scientific Publishers Ltd, Oxford, pp 189-216

Petkova-Andonova M, Imaishi H, Ohkawa H (2002) CYP92B1, a cytochrome $\mathrm{P} 450$, expressed in petunia flower buds, that catalyzes monooxidation of long chain fatty acids. Biosci Biotechnol Biochem 66:1819-1828

Pinot F, Beisson F (2011) Cytochrome P450 metabolizing fatty acids in plants: characterization and physiological roles. FEBS J 278:195-205

Printz B, Lutts S, Hausman JF, Sergeant K (2016) Copper trafficking in plants and its implication on cell wall dynamics. Front Plant Sci 7:601

Przybecki Z, Kowalczyk ME, Siedlecka E, Urbanczyk-Wochniak E, Malepszy S (2003) The isolation of cDNA clones from cucumber (Cucumis sativus $\mathrm{L}$.) floral buds coming from plants differing in sex. Cell Mol Biol Lett 8:421-438

Przybecki Z, Kowalczyk ME, Witkowicz J, Filipecki M, Siedlecka E (2004) Polymorphom of sexually different cucumber (Cucumis sativus L.) NIL lines. Cell Mol Biol Lett 9:919-933

Ramakers C, Ruijter JM, Deprez RHL, Moorman AF (2003) Assumption-free analysis of quantitative real-time polymerase chain reaction (PCR) data. Neurosci Lett 339:62-66

Rast MI, Simon R (2012) Arabidopsis JAGGED LATERAL ORGANS acts with ASYMMETRIC LEAVES2 to coordinate KNOX and PIN expression in shoot and root meristems. Plant Cell 24:2917-2933

Rea PA (2007) Plant ATP-binding cassette transporters. Annu Rev Plant Biol 58:347-375

Renner SS (2016) Pathways for making unisexual flowers and unisexual plants: moving beyond the "two mutations linked on one chromosome" model. Am J Bot 103:587-589
Rhee SJ, Seo M, Jang YJ, Cho S, Lee GP (2015) Transcriptome profiling of differentially expressed genes in floral buds and flowers of male sterile and fertile lines in watermelon. BMC Genom 16:914

Rodrigo-Moreno A, Andrés-Colás N, Poschenrieder C, Gunsé B, Peñarrubia L, Shabala S (2013) Calcium-and potassium- permeable plasma membrane transporters are activated by copper in Arabidopsis root tips: linking copper transport with cytosolic hydroxyl radical production. Plant Cell Environ 36:844-855

Rodriguez FI, Esch JJ, Hall AE, Binder BM, Schaller GE, Bleecker AB (1999) A copper cofactor for the ethylene receptor ETR1 from Arabidopsis. Science 283:996-998

Rutjens B, Bao D, Eck-Stouten V, Brand M, Smeekens S, Proveniers M (2009) Shoot apical meristem function in Arabidopsis requires the combined activities of three BEL1-like homeodomain proteins. Plant J 58:641-654

Sancenón V, Puig S, Mira H, Thiele DJ, Peñarrubia L (2003) Identification of a copper transporter family in Arabidopsis thaliana. Plant Mol Biol 51:577-587

Schmid KM (2015) Lipid metabolism in plants. In: Ridgway ND, McLeod RS (eds) Biochemistry of lipids, lipoproteins and membranes. Elsevier, Dordrecht, pp 113-147

Sede AR, Borassi C, Wengier DL, Mecchia MA, Estevez JM, Muschietti JP (2018) Arabidopsis pollen extensins LRX are required for cell wall integrity during pollen tube growth. FEBS Lett 592:233-243

Shannon P, Markiel A, Ozier O, Baliga NS, Wang JT, Ramage D et al (2003) Cytoscape: a software environment for integrated models of biomolecular interaction networks. Genome Res 13:2498-2504

Skarzyńska A, Pawełkowicz M, Pląder W, Przybecki Z (2016) The utility of optical detection system (qPCR) and bioinformatics methods in reference gene expression analysis. Proc SPIE 10031:1003130

Sulmon C, Gouesbet G, El Amrani A, Couée I (2007) Involvement of the ethylene-signalling pathway in sugar-induced tolerance to the herbicide atrazine in Arabidopsis thaliana seedlings. J Plant Physiol 164:1083-1092

Sun JJ, Li F, Li X, Liu XC, Rao GY, Luo JC et al (2010) Why is ethylene involved in selective promotion of female flower development in cucumber? Plant Signal Behav 5:1052-1056

Suzuki H, Rodriguez-Uribe L, Xu J, Zhang J (2013) Transcriptome analysis of cytoplasmic male sterility and restoration in CMS-D8 cotton. Plant Cell Rep 32:1531-1542

Szklarczyk D, Morris JH, Cook H, Kuhn M, Wyder S, Simonovic M et al (2017) The STRING database in 2017: quality-controlled protein-protein association networks, made broadly accessible. Nucleic Acids Res 45:D362-D368

Tatusov RL, Fedorova ND, Jackson JD, Jacobs AR, Kiryutin B, Koonin E et al (2003) The COG database: an updated version includes eukaryotes. BMC Bioinf 4:41

Terefe D (2005) Molecular genetic and physiological studies on the sex-determining $\mathrm{M} / \mathrm{m}$ and $\mathrm{A} / \mathrm{a}$ genes in cucumber (Cucumis sativus L). Dissertation, Universitat Hannover

Terefe D, Tatlioglu T (2005) Isolation of a partial sequence of a putative nucleotide sugar epimerase, which may involve in stamen development in cucumber (Cucumis sativus L.). Theor Appl Genet 111:1300-1307

Thomson B, Zheng B, Wellmer F (2017) Floral organogenesis: when knowing your ABCs is not enough. Plant Physiol 173:56-64

Trebitsh T, Staub JE, O’Neill SD (1997) Identification of a 1-aminocyclopropane-1-carboxylic acid synthase gene linked to the Female (F) locus that enhances female sex expression in cucumber. Plant Physiol 113:987-995

Usadel B, Poree F, Nagel A, Lohse M, Czedik-Eysenberg A, Stitt M (2009) A guide to using MapMan to visualize and compare 
Omics data in plants: a case study in the crop species. Maize Plant Cell Environ 32:1211-1229

Vandesompele J, De Preter K, Pattyn F, Poppe B, Van Roy N, De Paepe A et al (2002) Accurate normalization of real-time quantitative RT-PCR data by geometric averaging of multiple internal control genes. Genome Biol 3:research0034

Wang KL, Li H, Ecker JR (2002) Ethylene biosynthesis and signaling networks. Plant Cell 14:S131-S151

Wang Y, Zhang WZ, Song LF, Zou JJ, Su Z, Wu WH (2008) Transcriptome analyses show changes in gene expression to accompany pollen germination and tube growth in Arabidopsis. Plant Physiol 148:1201-1211

Wu T, Qin Z, Zhou X, Feng Z, Du Y (2010) Transcriptome profile analysis of floral sex determination in cucumber. J Plant Physiol 167:905-913

Xu C, Luo F, Hochholdinger F (2016) LOB domain proteins: beyond lateral organ boundaries. Trends Plant Sci 21:159-167

Yamasaki S, Fujii N, Takahashi H (2005) Hormonal regulation of sex expression in plants. Vitam Horm 72:79-110

Yang SF, Hoffman NE (1984) Ethylene biosynthesis and its regulation in higher plants. Annu Rev Plant Physiol 35:155-189

Yin T, Quinn JA (1995) Tests of a mechanistic model of one hormone regulating both sexes in Cucumis sativus (Cucurbitaceae). Am J Bot 82:1537-1546
Yoon GM, Kieber JJ (2013) ACC synthase and its cognate E3 ligase are inversely regulated by light. Plant Signal Behav 8:e26478

Yruela I (2005) Copper in plants, Braz. J Plant Physiol 17:145-156

Yuan HM, Xu HH, Liu WC, Lu YT (2013) Copper regulates primary root elongation through PIN1- mediated auxin redistribution. Plant Cell Physiol 54:766-778

Zhang D, Liang W, Yin C, Zong J, Gu F, Zhang D (2010) OsC6, encoding a lipid transfer protein, is required for postmeiotic anther development in rice. Plant Physiol 154:149-162

Zhang Y, Zhang X, Liu B, Wang W, Liu X, Chen C et al (2014) A GAMYB homologue CsGAMYB1 regulates sex expression of cucumber via an ethylene-independent pathway. J Exp Bot 65:3201-3213

Zhang B, Liu H, Ding X, Qiu J, Zhang M, Chu Z (2017) AtACS8 plays a critical role in the early biosynthesis of ethylene elicited by copper ions in Arabidopsis. J Cell Sci 131:jcs-202424

Zhu XF, Zhu CQ, Zhao XS, Zheng SJ, Shen RF (2016) Ethylene is involved in root phosphorus remobilization in rice (Oryza sativa) by regulating cell-wall pectin and enhancing phosphate translocation to shoots. Ann Bot 118:645-653

Publisher's Note Springer Nature remains neutral with regard to jurisdictional claims in published maps and institutional affiliations. 